\title{
Mechanochemistry of fluoride solids: from mechanical activation to mechanically stimulated synthesis
}

\author{
Gudrun Scholz ${ }^{1}$ (D)
}

Received: 4 November 2020 / Accepted: 14 January 2021 / Published online: 8 April 2021

(c) The Author(s) 2021

\section{Abstract}

This lecture text is focused on the comparatively young field of mechanochemistry of fluoride solids, considering both their mechanical activation and their mechanochemical synthesis. Beside a literature survey, the mechanochemical synthesis of binary fluorides $\mathrm{MF}_{2}, \mathrm{MF}_{3}$, of complex fluorides $\mathrm{MMgF}_{4}$, of solid solutions $\mathrm{M}_{x}^{\mathrm{a}} \mathrm{M}^{\mathrm{b}}{ }_{1-x} \mathrm{~F}_{2}$ or $\mathrm{M}_{1-x} \mathrm{Ln}_{x} \mathrm{~F}_{2+x}(\mathrm{Ln}$ : $\mathrm{Y}, \mathrm{Eu})$ and of fluorine-containing coordination polymers is presented. Owing to their interesting potential applications in the field of fluoride ion conductivity or luminescence properties when doped, most of the given examples are alkaline earth metal compounds. A short historical survey, remarks on peculiarities and consequences of mechanical activation as well as the necessary technical equipment for mechanochemical reactions precede the section.

\section{Graphic abstract}

$$
\mathrm{MR}_{2}+\mathrm{NH}_{4} \mathrm{~F}
$$

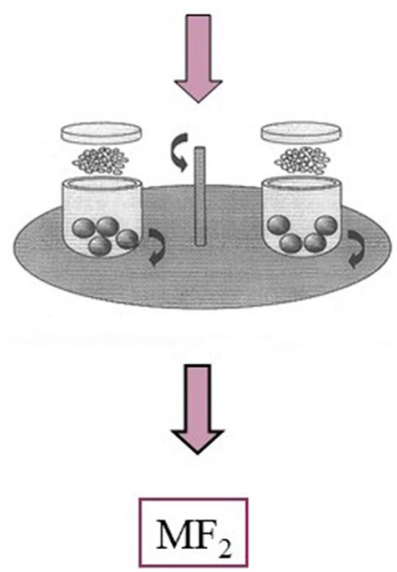

Keywords Mechanical activation $\cdot$ Mechanochemical synthesis $\cdot$ Solid fluorides

Gudrun Scholz

Gudrun.Scholz@rz.hu-berlin.de

1 Department of Chemistry, Humboldt-Universität zu Berlin, Brook-Taylor-Str. 2, 12489 Berlin, Germany 


\section{Introduction ${ }^{1}$}

Mechanochemistry is still not sufficiently present in chemistry textbooks. Therefore, it is hoped that this text will fill the gap.

Mechanically induced reactions have been known and used for thousands of years. Therefore, it is really surprising that mechanochemistry is both one of the less understood and one of the less studied fields of chemistry. Nevertheless a tremendous number of mechanochemical syntheses were successfully performed since the beginning of the twentyfirst century. Mechanochemical syntheses are for instance applicable to prepare inorganic and organic materials, cocrystals, intermetallic compounds, nanomaterials, active pharmaceutical ingredients or inorganic-organic hybrid materials. A comprehensive recent survey of applications of mechanochemistry is given by Baláž et al. [1]. The general possibility of mechanochemical syntheses is therefore related to all imaginable local bonding situations in solids, i.e. mechanically induced rupture and formation of covalent, ionic or metallic bonds along with the influence of mechanical forces on weak intra- and intermolecular interactions like hydrogen bridges.

Mechanically induced solid-state chemical reactions can be performed completely without solvents. Ideally, by-products disappear via the gaseous phase. As a consequence, solid-state mechanochemistry is an attractive alternative to classical, solvent-based syntheses routes and can be regarded as green chemistry. Moreover, metastable products or phases can be obtained which are not accessible using other synthesis strategies.

Ball milling techniques without additional solvents are widely used in mechanochemistry. Altogether one can observe the following phenomena involved in milling: on the one hand, a dramatic reduction of the particle sizes occurs, dependent on the milling tools down to the nanometre range and a possible amorphization of the starting materials. On the other hand, new compounds with good crystallinity can be built up during milling, and in addition, their crystallinity can be even improved with ongoing mechanical impact.

Mechanochemistry opens numerous potential applications of as-prepared materials. Therefore, the present contribution introduces first of all peculiarities of mechanochemical reactions and their consequences along with the necessary equipment, beside a short historical overview of the development of mechanochemistry at the beginning. Thereafter, examples of mechanical activation and mechanochemical syntheses of

\footnotetext{
1 The present article is a revised and extended version of the paper published in German on occasion of the 90th birthday of Prof. Dr. Lothar Kolditz in Leibniz Online 37 (2019), the journal of the Leibniz Sozietät der Wissenschaften zu Berlin e.V. (ISBN 1863-3285).
}

fluoride solids, especially of alkaline earth metal fluorides and fluorine-containing coordination polymers, are the focus of this publication.

The interest on binary fluorides and nanostructured solid solutions of fluorides with fluorite structure, especially alkaline earth metal fluorides, increased substantially during recent years. Two fundamental properties of these substances are responsible for this trend:

(i) Their fluoride ion conductivity, making them suitable as electrolyte materials for fluoride ion batteries or fluoride ion conductors in chemical sensors.

(ii) Their excellent luminescence properties in the case of doping with rare earth elements. The large band gap of fluorides and their optical transparency over a wide range are a big advantage for doping with rare earth ions. These properties allow innovative applications in displays, fluorescent ceramics, solar cells up to biological systems.

\section{Short historical survey}

Using traditional tools, i.e. a mortar and pestle, milling can be regarded as the first engineering technology starting as long ago as in the Stone Age. It was apparent very early on that much more happens than only obvious grinding and comminution processes. One of the very early "applications" is the generation of fire by friction. The oldest known document directly related to chemistry was written by Theophrastus of Eresos, a scholar of Aristotle, in 315 BCE [2]. The comminution of cinnabar (mercury sulfide, $\mathrm{HgS}$ ) in a copper mortar led to the formation of mercury $(\mathrm{Hg})$, i.e. to the reduction of mercury cations by copper metal. However, only at the end of the nineteenth century, i.e. about 2000 years later, were systematic investigations published on chemical reactions initiated by mechanical energy.

On the basis of his systematic studies on mechanically induced decomposition reactions of silver halides and mercury halides, Matthew Carey Lea (1823-1897) is regarded today as the founder of mechanochemistry [2-5] (Fig. 1). Lea found that mechanically induced chemical reactions can result in different products than thermally induced chemical reactions, a situation which was confirmed later for many reactions.

Despite these encouraging developments, publications concerning mechanochemistry were rare in the first half of the twentieth century. At this point, however, one has to mention the important merit of Wilhelm Ostwald (1853-1932, Fig. 1), who introduced for the first time the general term mechanochemistry into the systematics of chemistry [6]. Only in the 1960s did mechanochemistry experience a considerable revival. Different groups began to work in this field, especially in the Soviet Union, in Eastern Europe 


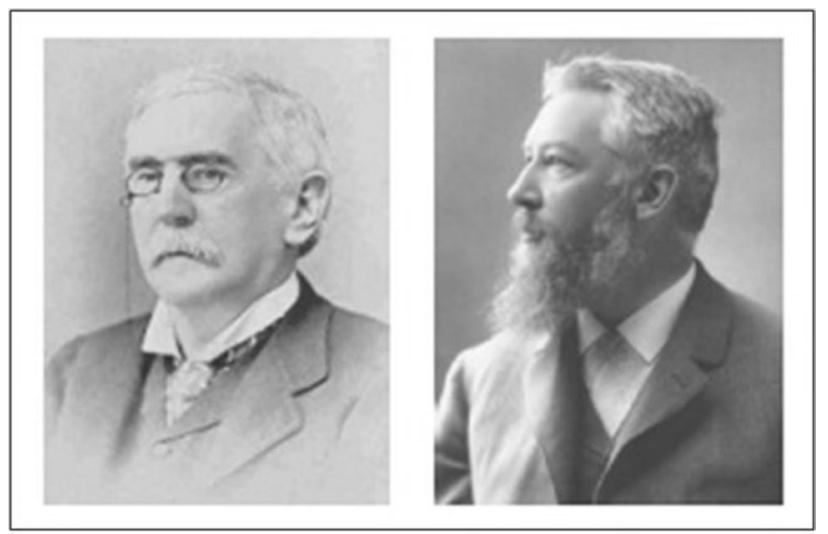

\section{Matthew Carey Lea Wilhelm Ostwald $(1823-1897)$ $(1853-1932)$}

Fig. 1 Pictures of Matthew Carey Lea, who is regarded as the founder of mechanochemistry, and of Wilhelm Ostwald, who introduced the term mechanochemistry into the classification of chemistry. Reproduced from [4]. Copyright 2005 Wiley-VCH Weinheim, All rights reserved

and in the GDR. The development of mechanochemistry in this period is associated with well-known scientists like Boldyrev and Avvakumov (Novosibirsk), Butyagin (Moscow) and Zhurkow (Leningrad), in the GDR with Thiessen and Heinicke (Berlin), in Czechoslovakia with Tkácova and Baláž (Košice), in Hungary with Juhász and in Japan with Kubo and Senna [2].

In this period the scientific questions were mainly focused on the mechanical activation and mechanochemical reactions of inorganic solids, i.e. reactions of oxides, silicates as well as the processing and handling of ores. The field of mechanical alloying developed independently of this direction. These developments, occurring almost in parallel, were brought together with the foundation of the International Mechanochemical Association in 1984. The latter initiated the International Conference on Mechanochemistry and Mechanical Alloying (INCOME), which took place in 1993 for the first time in Košice and every 3 years thereafter; the last one occurred in 2017 again in Košice.

Central questions on these conferences were and are questions on mechanical and mechanochemical alloying, the processing of ores, the synthesis of complex oxides (ceramics, dielectrics) and other inorganic materials, the synthesis of pharmaceuticals, but also questions of hydrogen storage and batteries ${ }^{2}$. With the last INCOME conference in 2017 it became obvious that mechanochemistry developed enormously also in other chemical fields since the beginning of

\footnotetext{
${ }^{2}$ Detailed information about the history of mechanochemistry is given in [2-5] including references therein.
}

the 1990s. Meanwhile, this field of chemistry is also represented by several research groups in Western Europe and in the USA [7].

Nowadays, mechanochemistry is-beside inorganic materials-present in nearly all research areas of chemistry. These areas range from polymer chemistry, the formation of inorganic-organic hybrid materials, zeolites and metal-organic frameworks, from pharmaceutically relevant organic compounds, co-crystals, fullerenes, the field of heterogeneous catalysis, mechanochemical reactions with gaseous reactants [8], organo-metal complexes, metal-catalysed organic reactions, up to solvent-free mechanochemical reactions in organic chemistry (see also [1] and references therein). In a special issue of Chemical Society Reviews [9] review articles have been published representing nearly all fields of mechanochemistry, which show the aforementioned development. Still not present in that special issue was the younger field of mechanochemistry of fluoride solids, which is the focus of the present contribution.

So: what is mechanochemistry? Until now this term introduced by Ostwald in 1919 and the definition given by Heinicke in 1984 [10] are still valid: It is a field of chemistry dealing with chemical and physicochemical changes of substances in all states of matter, due to the influence and action of mechanical energy.

The present contribution is exclusively attributed to substances in the solid state, to solids, which are usually used as powders for mechanochemical reactions. At this point I recommend to read in addition the lecture text by Senna [11], who introduced the reader (i) to the basics of solid-state chemical reactions, (ii) to the role of defects and diffusion in solids for their reactivity and (iii) who compared changes in solids due to heating in comparison with milling processes.

Mechanical energy can be applied in different ways. Milling is one common option, but also the application of pressure or sonication (ultrasound) [12] is possible. All kinds of mechanical energy lead to peculiarities on and in the solids and to implications for occurring chemical reactions.

\section{Peculiarities and consequences of mechanical activation}

Grinding of solids diminishes the particle size. Dependent on the milling tools and the applied energy, it is possible to reduce the particle size down to the nanometer range. Starting from a phase pure solid as the material to be ground a mechanical activation occurs. What happens? The milling permanently produces fresh and new surfaces. Along with the reduction of the particle size, the surface to volume ratio is increased. Material abrasion, plastic deformations, inclusions of impurities or accumulation of defects are further issues changing the reactivity of the solid. The milling process has consequences on the long- and short-range order 
of the material and ends up with a mechanically distorted solid material. Dependent on the starting material the distortion can lead to a complete loss of the lattice periodicity with the solid material being X-ray amorphous after milling. Such a situation can frequently be observed in the case of oxides. Emissions of photons, electrons as well as lattice components were directly proven during the mechanical activation of inorganic materials like oxides. Static charges and electrostatic discharges were observed as well as local warming $[10,13]$. As result of a mechanical treatment, especially using high-energy ball mills, materials with changed chemical and physical properties are obtained. Improved catalytic activities, increased solubilities, a changed sorption behaviour up to changed chemical reaction pathways have been observed. The application of mechanical energy allows new chemical reaction pathways, which are limited by diffusion processes in solid-state chemistry induced classically by thermal energy. Different, new materials or even metastable compounds are accessible. The treatment of silver chloride is a classical example. A thermal treatment initiates melting and evaporation of silver chloride. The result of the mechanical treatment, however, is the formation of metallic silver particles and chlorine gas [4]. The latter reaction, which was the subject of research by Carey Lea [2-4], can be used nowadays to produce silver nanoparticles with high-energy mills.

Many examples exist for the changed kinetic and thermodynamic behaviour of mechanically activated materials. This situation implies numerous questions regarding the mechanism of mechanochemically initiated solid-state reactions, which is still by far not completely understood. Moreover, one can surely say that only a singular mechanism of mechanochemical reactions will not exist. The reason is provided by very different bonding situations in the mechanochemically treated materials, which demand different milling conditions.

Nevertheless, the magma-plasma model $[10,14]$ should be mentioned, which was the first model in mechanochemistry. It was developed in the 1960s, especially for hard and brittle inorganic materials. According to this model a large amount of energy is released on the contact area of the colliding particles, finally responsible for the formation of plasma-like states. This assumption was proven by the emission of highly excited fragments of the solid substance, by the emission of photons and electrons on an extremely short timescale $[3,10,14]$. The surface on the contact point of solid grains is highly disordered and local temperatures up to $10,000 \mathrm{~K}$ can be achieved. In this concept numerous excitation processes, characterized by different relaxation times, are important $[3,13]$. Further models and attempts exist to explain the mechanistic aspects of mechanochemical reactions. All of them are presented in the monograph of Baláž [3], including their references for further reading.
Most of them were developed towards the end of the twentieth century.

\section{Technical equipment for mechanochemical reactions}

Since the majority of mechanochemical reactions is performed by milling the reactants, only milling tools are considered in this present contribution. A lot of different milling tools exist, which can be used for mechanical activation or mechanochemical reactions. A very simple one is a mortar and pestle. Simple mortar mills, vibrations mills, ball mills or planetary mills are used along with pinned disk mills or attritors (stirred ball mills) [3, 10]. Which mill is finally used depends both on the material to be studied and the necessary energy input.

For academic purposes, in the research laboratory, simple vibration mills (Fig. 2a) are usually sufficient for many chemical reactions, especially in the field of organic chemistry. In addition, planetary ball mills (Fig. 2b) are a widely used standard for high-energy ball milling. Two kinds of mills are shown as examples in Fig. 2 which are typically used in the laboratory (see also websites of companies Fritsch and Retsch ${ }^{3}$ ). Moreover, the most simple mechanical device, a mortar and pestle, is shown in Fig. 2c for completeness.

The milling tool of the vibration mill (Fig. 2a) consists of two hemispheres and usually one to two milling balls of the same material. The material to be ground is placed in the hollow sphere. After fixing the cover the vibrations occur vertically, in most cases with a frequency of $50 \mathrm{~Hz}$. Very often the milling tool is made of stainless steel. But polymer materials were also successfully used, because they additionally allow an in situ coupling to modern analytical methods (e.g. Ref. [15]). The grinding beakers of a planetary mill are rotatable mounted on a base plate (Fig. 2b). Base plate and milling beaker move contrarily, giving the mill therefore the name planetary mill (cf. Fig. 2b, with the mill Pulverisette 7, Fritsch company, as prototype of a planetary mill). As a result of the high-energy impact, milling beakers and balls are manufactured from hard, abrasion-resistant materials like silicon nitride, zirconium oxide, corundum, tungsten carbide or hardened steel.

\section{Mechanochemistry of fluoride solids}

Studies on mechanochemistry of fluoride solids started with few exceptions comparatively late, only in the beginning of the twenty-first century. Investigations on the synthesis of

\footnotetext{
3 https://www.fritsch.de/probenaufbereitung/mahlen/; https://www. retsch.de/de/produkte/.
} 
Fig. 2 Frequently used versions of mechanical devices: a vibration mill: Pulverisette 23; b planetary mill: Pulverisette 7 , classic line; (reproduced with permission of the Fritsch company, cf. footnote 3); c simple mortar and pestle a

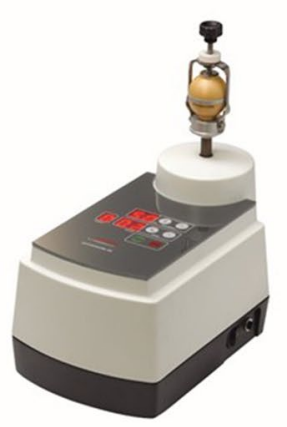

(i) ternary fluorides $\mathrm{AZnF}_{3}\left(\mathrm{~A} ; \mathrm{K}, \mathrm{Na}, \mathrm{NH}_{4}\right)$ with perovskite structure [16], (ii) complex fluorides $\mathrm{ARF}_{4}$ (A: alkaline metal cations, R: rare earth element cations) [17] or (iii) of lanthanum oxide fluoride $\mathrm{LaOF}$ from $\mathrm{LaF}_{3}$ and $\mathrm{La}_{2} \mathrm{O}_{3}$ [18] have to be mentioned. All of them were focused on the excellent optical properties of the materials as one possible application. On the other hand, inorganic fluorides are known as fluoride ion conductors, a property which can be explored in electrochemical devices or batteries. The small size and the single negative charge allow a fast movement of fluoride ions in solids.

Staring from crystalline $\mathrm{SnF}_{2}$ and $\mathrm{PbF}_{2}$, both are well known as very good fluoride ion conductors, ternary and quaternary fluorides have been mechanochemically synthesized [19-21]. The systems $\mathrm{MF}_{2}-\mathrm{SnF}_{2}\left(\mathrm{MSnF}_{4}, \mathrm{M}: \mathrm{Pb}, \mathrm{Ba}\right)$ are the fastest fluoride ion conductors known nowadays [22-24]. This high conductivity can be in addition considerably increased by the mechanochemical synthesis. Structural disorder in the grain surfaces, small particle sizes, introduced defects and short diffusion paths are responsible for this additional effect [25-28]. For example, the high electric conductivity of $\mathrm{PbSnF}_{4}$ is shown in Fig. 3 as a function of the temperature. Higher temperature (lower $T^{-1}$ values) results in a strong increase of the electric conductivity. Finally, solid solutions of the general composition $\mathrm{Pb}_{1-x} \mathrm{Sn}_{x} \mathrm{~F}_{2}$ have also been mechanochemically synthesized [29, 30].

However, mechanochemical syntheses were not only restricted to the albeit promising chemical system $\mathrm{PbF}_{2}-\mathrm{SnF}_{2}$. Thanks to the successful activities of the research groups of Heitjans (Leibniz University Hannover, Germany) and Wilkening (University Graz, Austria) the number of mechano-synthesized fluorides was remarkably expanded. Ion dynamics in these new solids was substantially studied by solid-state NMR and impedance spectroscopy, respectively.
C
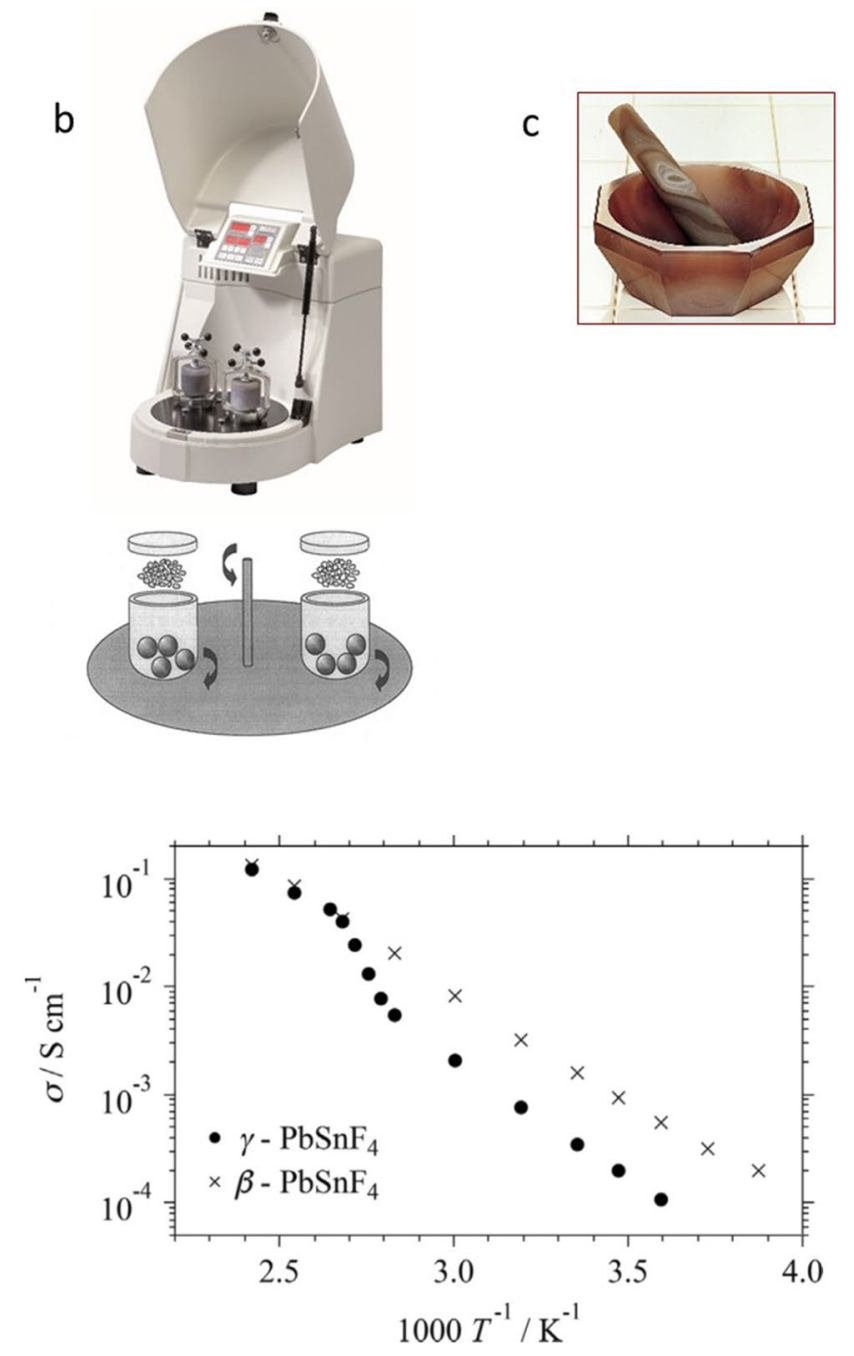

Fig. 3 Temperature dependence of the electrical conductivities, $\sigma(T)$, for $\gamma-\mathrm{PbSnF}_{4}$ (closed circles) and $\beta-\mathrm{PbSnF}_{4}$ (cross marks). Reproduced from [27]. Copyright 2017 Elsevier Masson SAS. All rights reserved

The mechanochemical synthesis of fluorides with inverse perovskite structure like $\mathrm{BaLiF}_{3}[31-34]$ or $(\mathrm{Ba}, \mathrm{Sr}) \mathrm{LiF}_{3}[35$, 36] was very successful. The mutual substitution of $\mathrm{Ba}^{2+}$ with $\mathrm{Sr}^{2+}$ ions was impressively demonstrated using high-speed ${ }^{19} \mathrm{~F}$ magic angle spinning (MAS) NMR spectra (Fig. 4), which allowed the distinct discrimination between the five possible local structure units around fluorine.

Furthermore, the successful mechanochemical synthesis of the following complex fluorides has been reported: $\mathrm{BaMgF}_{4}$ [37, 38], $\mathrm{SrMgF}_{4}$ [39], $\mathrm{BaSnF}_{4}$ [40] $\mathrm{RbSn}_{2} \mathrm{~F}_{5}$ [41], $\mathrm{NaSn}_{2} \mathrm{~F}_{5}$ [42], $\mathrm{KSn}_{2} \mathrm{~F}_{5}$ [43] and $\mathrm{Li}_{3} \mathrm{AlF}_{6}$ [44]. Moreover, the mechanochemical synthesis was successful for solid solutions of (i) alkaline earth metal fluorides or $\mathrm{PbF}_{2}$ with cubic symmetry $\mathrm{M}_{1-x}^{\mathrm{I}} \mathrm{M}^{\mathrm{II}}{ }_{x} \mathrm{~F}_{2}$ (M: Ca, Sr, Ba, Pb) (fluorite structure) [45-49], of (ii) alkaline earth metal fluorides with rare earth fluorides or $\mathrm{YF}_{3}[50-54]$ or of (iii) $\mathrm{SnF}_{2}$ with alkaline metal fluorides [55, 


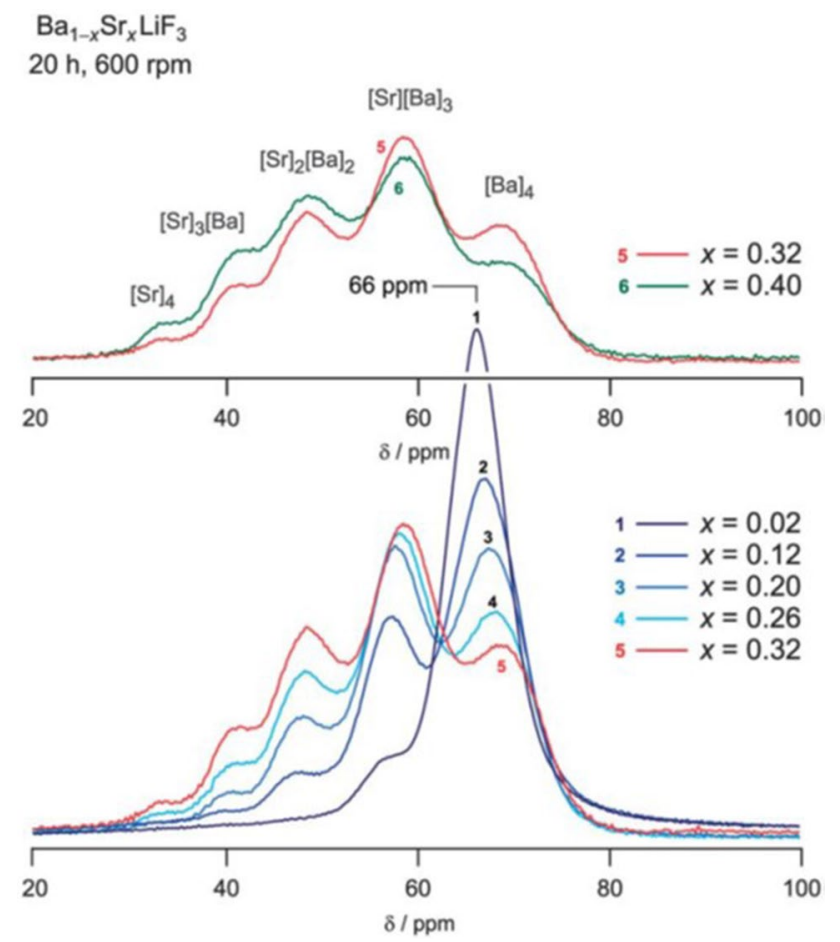

Fig. 4 Solid-state ${ }^{19} \mathrm{~F}$ MAS NMR spectra of mechanochemically synthesized $\mathrm{Ba}_{1-x} \mathrm{Sr}_{x} \mathrm{LiF}_{3}$ with different compositions. Data were recorded at $471 \mathrm{MHz}$ and a spinning speed of $60 \mathrm{kHz}$. Reproduced from [35] with permission from The Royal Society of Chemistry

56]. The authors were able to show that the mechanochemical route, partially combined with thermal post-treatment, is a simple synthesis method for nanocrystalline fluoride solids [57, 58]. All of the mentioned compounds are fast fluoride ion conductors after mechanical treatment. Preishuber-Pflügl and Wilkening gave a nice overview of local structures and ion dynamics in such defect-rich fluorides listed earlier [38]. Moreover, Patro very recently published an overview of the influence of milling process variables in a planetary mill on the synthesis and ion transport properties of fast fluoride ion conductors [59].

All syntheses mentioned above started from commercially available binary crystalline fluorides $\mathrm{MF}_{2}, \mathrm{MF}$ or $\mathrm{MF}_{3}$. Dependent on the desired final composition, their molar ratios were adjusted and their mixed fluoride powders were added into the grinding beakers, usually under dry conditions. Thus, a milling of solid fluorides was performed, which makes a serious mechanical impact necessary resulting finally in many hours of high-energy ball milling.

\section{Mechanical activation}

Beside the mechanically induced synthesis of aforementioned solid solutions or complex fluorides, only a few publications exist which focused on milling of pure crystalline fluorides and the effects on their structure and properties. Known are milling experiments with $\mathrm{BaF}_{2}$ [60], $\mathrm{SnF}_{2}, \mathrm{CaF}_{2}[47,48]$ and $\mathrm{AlF}_{3}$. Patro et al. were able to show that milling time, while keeping all other milling conditions unchanged, has a significant effect on crystallite sizes and micro-strains of $\mathrm{SnF}_{2}$ particles [21]. Impedance measurements demonstrated that the DC conductivity is reciprocally proportional to the crystallite size. It means that both properties can be adjusted using ball milling techniques.

The influence of high-energy ball milling on crystalline $\mathrm{CaF}_{2}$ was studied in our group [61] and also later by Abdellatief et al. [62]. The main analytical techniques used were $\mathrm{X}$-ray powder diffraction, ${ }^{19} \mathrm{~F}$ solid-state NMR, but also transmission electron microscopy (TEM). One important result, especially in comparison with oxide compounds, is a missing detectable amorphization of the fluoride powder samples after milling. And if at all, it can then only be found at the grain boundaries of the small particles. Only nanocrystalline $\mathrm{CaF}_{2}$ particles are obtained by applying even strongest mechanical impacts. Beside a broadening of the X-ray reflections and ${ }^{19} \mathrm{~F}$ resonances, the spin lattice relaxation time $T_{1}$ of the ${ }^{19} \mathrm{~F}$ nuclei gives a sensitive indication for the influence of the mechanical impact $[61,62]$. While for the commercial crystalline $\mathrm{CaF}_{2}$ a $T_{1}$ time $\left({ }^{19} \mathrm{~F}\right)$ of $91.2 \mathrm{~s}$ was determined, $4 \mathrm{~h}$ of milling in a planetary ball mill decrease this time to $3.9 \mathrm{~s}$ [61]. Moreover, increased fluoride ion conductivities were achieved using $\mathrm{CaF}_{2}$ samples with enhanced surface defect structures obtained by the application of vapour pressure followed by high-energy ball milling [63, 64].

A similar effect, i.e. the formation of nanocrystalline particles, was observed on the mechanical activation of $\alpha-\mathrm{AlF}_{3}$, the stable rhombohedral phase of aluminium fluoride [65] as well. The ${ }^{19} \mathrm{~F}$ spin lattice relaxation time was reduced from $175.8 \mathrm{~s}$ (crystalline starting material) to $5.4 \mathrm{~s}$ for the nanocrystalline sample after $16 \mathrm{~h}$ of milling.

Obviously, here the comminution of crystallites is also the dominant process during milling. In addition, the mechanical impact generates both Brønsted and Lewis acid sites on the surface of aluminium fluoride. In contrast to the crystalline starting material, the nanocrystalline $\alpha-\mathrm{AlF}_{3}$ sample prepared by milling is catalytically active. This was proven by the dismutation reaction of $\mathrm{CHClF}_{2}$. In addition, the proportion of Brønsted and Lewis acid sites can be adjusted by the chosen atmosphere during milling. Dry milling produces mainly Lewis acid sites, whereas air milling results in both Brønsted and Lewis acid sites [65].

Another powerful and flexible approach to obtain nanoscaled metal fluorides is the fluorolytic sol-gel synthesis, which was comprehensively documented in the lecture text by Kemnitz et al. ([66] and references therein). 


\section{Mechanochemical synthesis: fluorination in the mill}

The mechanochemical synthesis of solid fluorides, solid solutions of fluorides or complex fluorides with distinguished properties starting from powders is in general possible along two different reaction pathways:

The first way was followed in all publications cited above. The mechanochemical synthesis was carried out using different binary fluorides $\mathrm{MF}_{n}$ as reactants, i.e. all used reactants were already fluorine compounds. The second possible pathway was discovered and then followed systematically in our group at Humboldt-Universität zu Berlin.

The general reaction principle of all examples mentioned hereinafter is the fluorination of fluorine-free metal compounds $\mathrm{MX}_{n}$ like metal acetates, carbonates, hydroxides or alkoxides by milling with ammonium fluoride $\left(\mathrm{NH}_{4} \mathrm{~F}\right)$ directly in the planetary mill. It means that both the fluorination and the chemical reaction take place only under the influence of a mechanical impact [see, for example, also Eq. (1)].

During the mechanochemical synthesis of coordination polymers, perfluorinated organic compounds were used exclusively in addition to ammonium fluoride as fluorinating agent.

First of all, however, the idea of fluorination of fluorinefree reactants in the mill was followed to synthesize binary fluorides themselves in a mechanochemical way.

\section{Binary fluorides: $\mathrm{MF}_{2}$}

After a first attempt to synthesize $\mathrm{CaF}_{2}$ using $\mathrm{CaCO}_{3}$ and $\mathrm{NH}_{4} \mathrm{~F}$ as reactants [61], the general possibility of a mechanochemical synthesis of binary fluorides was published in 2012 for the first time [67]. The reaction according to Eq. (1) provides an easy, fast, direct and solvent-free access to nanocrystalline alkaline earth metal fluorides $\mathrm{MF}_{2}$.
$\mathrm{Mg}\left(\mathrm{CH}_{3} \mathrm{COO}\right)_{2} \cdot \mathrm{H}_{2} \mathrm{O}, \quad \mathrm{Mg}\left(\mathrm{CH}_{3} \mathrm{COO}\right)_{2} \cdot 4 \mathrm{H}_{2} \mathrm{O}$, $\mathrm{Mg}(\mathrm{OH})_{2}\left(\mathrm{CO}_{3}\right)_{4} \cdot 4 \mathrm{H}_{2} \mathrm{O}$ and $\mathrm{Mg}\left(\mathrm{CH}_{3} \mathrm{CH}_{2} \mathrm{O}\right)_{2}$. However, only in the case of $\mathrm{Mg}\left(\mathrm{CH}_{3} \mathrm{COO}\right)_{2} \cdot 4 \mathrm{H}_{2} \mathrm{O}$ as reactant can $\mathrm{MgF}_{2}$ (crystallizing with rutile structure) be synthesized in this way, though not phase pure.

This mechanochemical synthesis can be further simplified using alkaline earth metal hydroxides or hydroxide hydrates as reactants, which holds for $\mathrm{Ca}^{2+}, \mathrm{Sr}^{2+}$ and $\mathrm{Ba}^{2+}$ as metal cations. De facto, a mechanical impact is here no longer necessary with these reactants. Simply shaking the two solid powdered reactants for $30 \mathrm{~s}$ is sufficient (cf. Eq. (1), [67], see also Fig. 5b and the illustration given in Fig. 6). Later we were able to show that even simple mixing with a spatula works [68].

The contact of hydroxyl groups (water) with ammonium fluoride leads presumably to additional local formation of HF, which might accelerate the fluorination of the starting material. Such as-prepared nanocrystalline samples possess fluoride ion conductivities, which are astonishing high and distinctly higher than those of comparable microcrystalline samples [68].

Also lead fluoride $\mathrm{PbF}_{2}$ can be mechanochemically synthesized according to Eq. (1) [69]. Here, the choice of the fluorine-free precursor compound is decisive for the $\mathrm{PbF}_{2}$ phase finally formed. The usage of lead oxide $\mathrm{PbO}$ results in the orthorhombic $\alpha-\mathrm{PbF}_{2}$ phase, whereas the usage of lead acetate $\mathrm{Pb}\left(\mathrm{CH}_{3} \mathrm{COO}\right)_{2}$ results in the cubic $\beta-\mathrm{PbF}_{2}$ phase (fluorite structure). Starting with lead carbonate results in a mixture of both phases [69] (see also Fig. 7).

A similar chemical pathway was followed by Subirana Manzanares et al. [70]. The starting samples $\mathrm{Pb}\left(\mathrm{CH}_{3} \mathrm{COO}\right)_{2} \cdot 3 \mathrm{H}_{2} \mathrm{O}$ and $\mathrm{NH}_{4} \mathrm{~F}$ were ground in a mortar and organic additives, e.g. citric acid or amines, controlled the formation of the orthorhombic and the cubic phase of $\mathrm{PbF}_{2}$, respectively. Here, the use of amines favours the formation of the orthorhombic phase of $\mathrm{PbF}_{2}$ [70].

\section{$\mathrm{MX}_{2}+2 \mathrm{NH}_{4} \mathrm{~F} \quad \longrightarrow \quad \mathbf{M F}_{2}+2 \mathrm{NH}_{3} \uparrow+2 \mathrm{HX} \uparrow$}

For alkaline earth metal fluorides crystallizing in fluoritestructure (M: Ca, Sr, Ba) the synthesis according to Eq. (1) is possible, almost independent of the kind of the fluorinefree reactant [67]. All formed by-products leave the mill via the gaseous phase. The as-prepared alkaline earth metal fluorides are nanocrystalline and phase pure. For example, the X-ray powder diffractograms of mechanochemically synthesized $\mathrm{BaF}_{2}$ [according to Eq. (1)] are shown in Fig. 5.

For magnesium fluoride this situation is different. The following magnesium compounds were tested as starting materials: $\mathrm{Mg}(\mathrm{OH})_{2}, \mathrm{MgO}, \mathrm{Mg}\left(\mathrm{CH}_{3} \mathrm{COO}\right)_{2}$,
All in all it is worth mentioning that all mechanochemical reactions were performed under normal conditions. An increased humidity or an increased content of crystal water in the reactants had a positive effect on the formation of binary fluorides $\mathrm{MF}_{2}$.

\section{Binary fluorides: $\mathrm{MF}_{3}\left(\mathrm{AlF}_{3}, \mathrm{GaF}_{3}\right)$}

Unfortunately, it was not possible to transfer the successful mechanochemical synthesis principle of alkaline earth metal fluorides (Eq. 1) to the formation of earth metal fluorides. 
Fig. 5 X-ray powder diffractograms taken after reaction of $\mathrm{Ba}(\mathrm{OH})_{2} \cdot 8 \mathrm{H}_{2} \mathrm{O}$ with $\mathrm{NH}_{4} \mathrm{~F}$ $(\mathrm{Ba} / \mathrm{F}=1: 2)$ : a after $4 \mathrm{~h}$ milling in the planetary mill, $\mathbf{b}$ after 30 s shaking, c after thermal treatment in a quasi-closed $\mathrm{Pt}$ crucible (Q-crucible), $\mathbf{d}$ after thermal treatment in an open Pt crucible. For comparison, the diffractogram of crystalline $\mathrm{BaF}_{2}$ is given as reference. Reproduced from [67]. Copyright 2012 Elsevier Masson SAS. All rights reserved

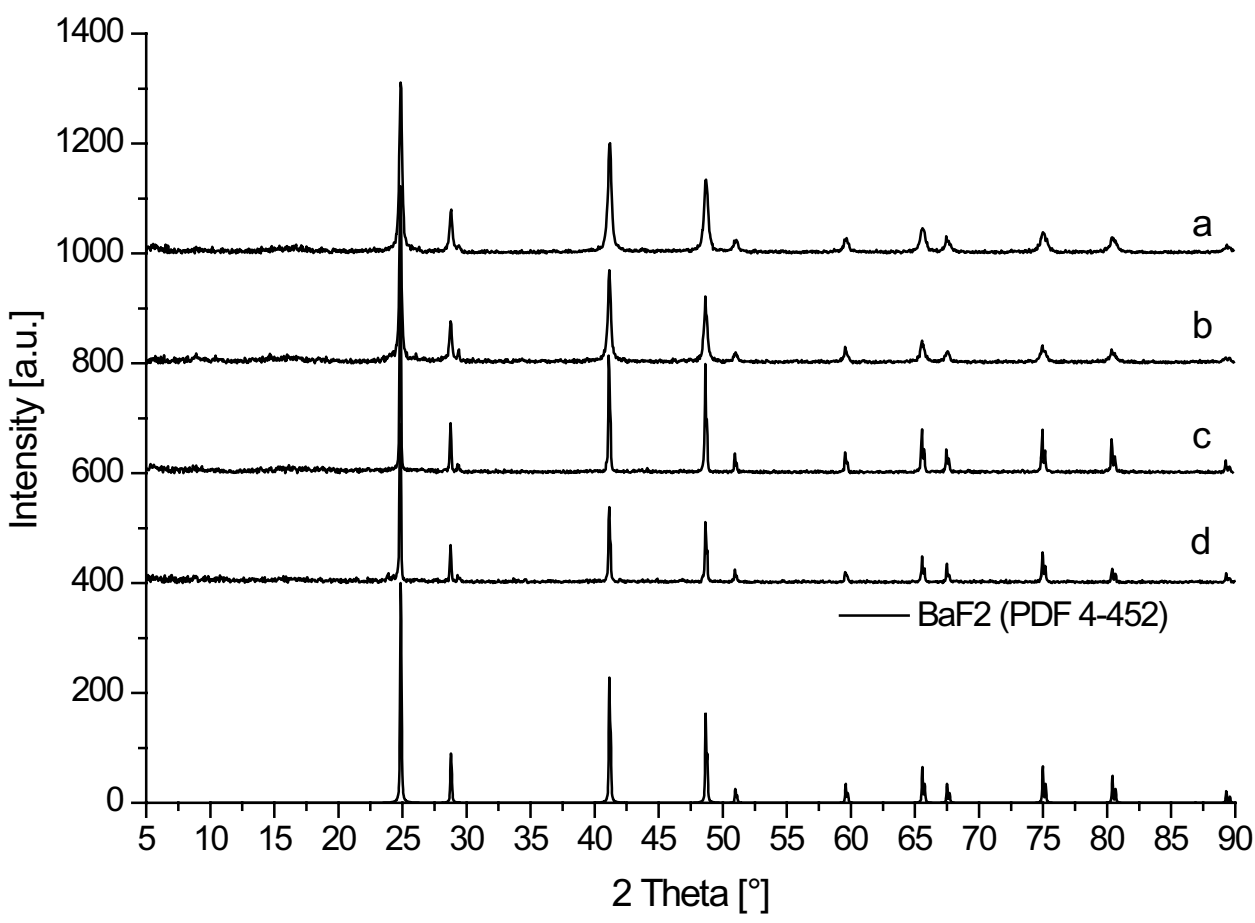

Extensive studies to synthesize aluminium fluoride according to Eq. (1) led, independent of the starting material $\left(\mathrm{Al}(\mathrm{OiPr})_{3},{ }^{4} \mathrm{AlOOH}, \mathrm{Al}\left(\mathrm{CH}_{3} \mathrm{COO}\right)_{2} \mathrm{OH}\right)$, always to the same result: the thermodynamically stable ammonium hexafluoroaluminate $\left(\left(\mathrm{NH}_{4}\right)_{3} \mathrm{AlF}_{6}\right)$ is formed as long as $\mathrm{NH}_{4}{ }^{+}$ions are available during the chemical reaction [71], Eq. (2) (Fig. 8).
Substitution of $\mathrm{NH}_{4} \mathrm{~F}$ by e.g. $\mathrm{NaF}$ results in remaining $\mathrm{Na}^{+}$ions in the matrix. And in this special combination the formation of cryolite $\left(\mathrm{Na}_{3} \mathrm{AlF}_{6}\right)$ or chiolite $\left(\mathrm{Na}_{5} \mathrm{Al}_{3} \mathrm{~F}_{14}\right)$, i.e. the formation of complex fluorides, can be observed [73, 74].

\section{$\mathrm{AlX}_{3}+6 \mathrm{NH}_{4} \mathrm{~F} \quad \longrightarrow\left(\mathrm{NH}_{4}\right)_{3} \mathrm{AlF}_{6}+3 \mathrm{NH}_{3} \uparrow+3 \mathrm{HX} \uparrow$}

Similar to Eq. (2) Lu et al. [72] mechanochemically synthesized ammonium hexafluorogallate, $\left(\mathrm{NH}_{4}\right)_{3} \mathrm{GaF}_{6}$, starting from $\mathrm{GaF}_{3} \cdot 3 \mathrm{H}_{2} \mathrm{O}$ and $\mathrm{NH}_{4} \mathrm{~F}$. However, the authors were not able to prepare gallium fluoride $\left(\mathrm{GaF}_{3}\right)$.

Consequently, the formation of binary fluorides $\mathrm{MF}_{3}$ would require another fluorinating agent without ammonium ions. This situation is problematic bearing in mind the requirement that additionally formed compounds should disappear via the gaseous phase.

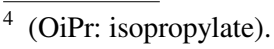

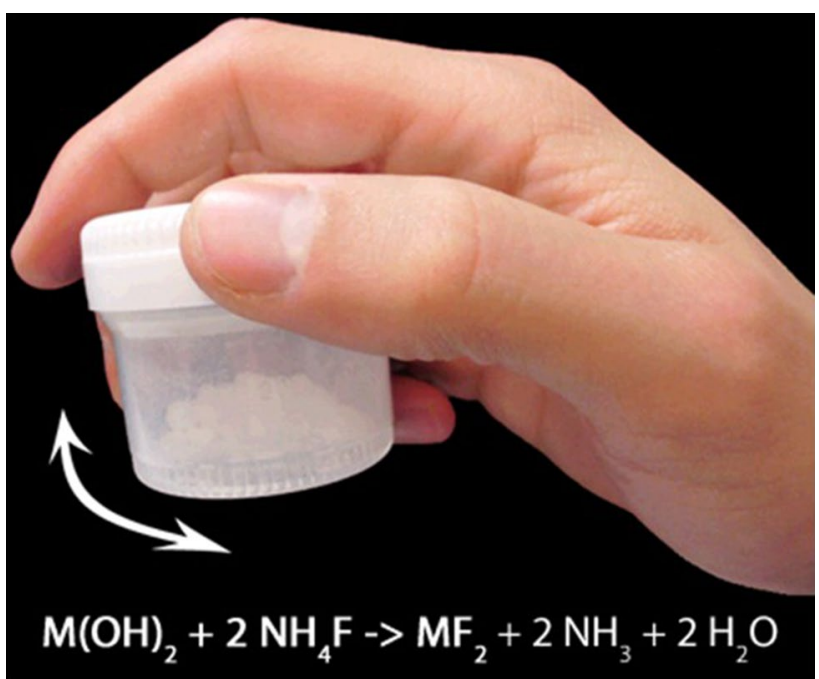

Fig. 6 Illustration of the preparation of alkaline earth metal fluorides $\mathrm{MF}_{2}$, simply by shaking. Reproduced from [67]. Copyright 2012 Elsevier Masson SAS. All rights reserved 
Fig. 7 Scheme for the mechanochemical synthesis of orthorhombic $\alpha-\mathrm{PbF}_{2}$ (from $\mathrm{PbO}$ ) and cubic $\beta-\mathrm{PbF}_{2}$ (from $\mathrm{Pb}(\mathrm{OAc})_{2}$ phases $)$. Reproduced from [69]. Copyright 2017 Elsevier Masson SAS. All rights reserved

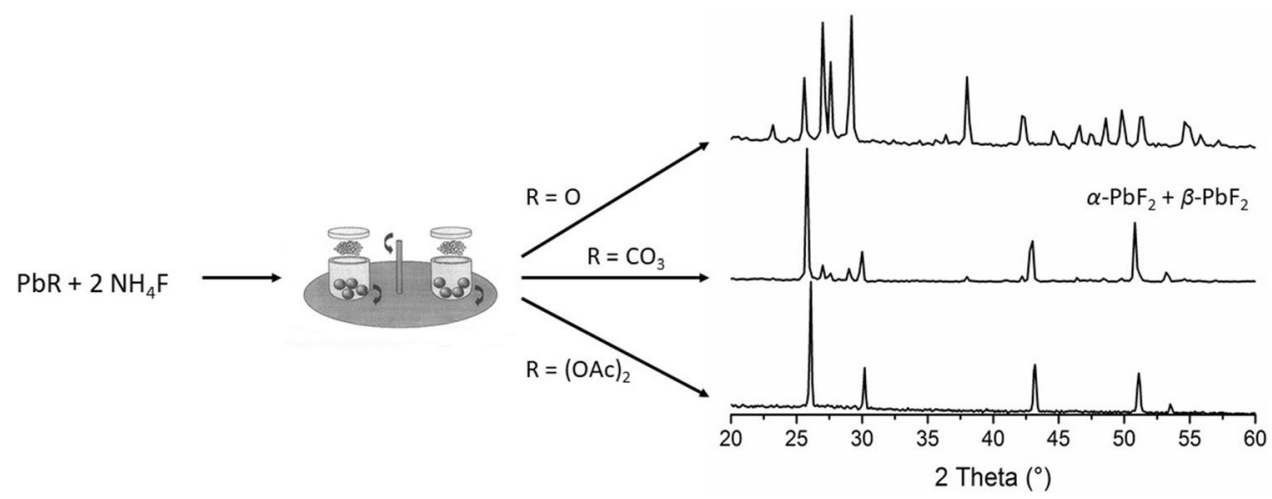

As already observed in the case of the formation of binary fluorides $\mathrm{MF}_{2}$, the presence of humidity or an adjusted water content of the starting compounds promotes the formation of complex fluorides with different product composition. The latter was tested for the reaction of $\mathrm{NaF}$ with $\mathrm{AlF}_{3}$ to form cryolite or chiolite (Fig. 9). It demonstrates that an adjusted degree of humidity results in different product compositions [74].

In principle, a mechanochemical synthesis of $\mathrm{AlF}_{3}$ is only possible if further cations can be avoided. Surprisingly, a milling attempt using $\beta-\mathrm{AlF}_{3} \cdot 3 \mathrm{H}_{2} \mathrm{O}$ with the aim simply to remove the crystal water and to end up with $\mathrm{AlF}_{3}$ is not successful, which is in contradiction to the classical
$\mathrm{MMgF}_{4}$ depends in addition on the radius of the alkaline earth metal cation. With decreasing radius of the cation $\mathrm{M}^{2+}$ $\left(\mathrm{Ba}^{2+}>\mathrm{Sr}^{2+}>\mathrm{Ca}^{2+}\right)$ the formation of $\mathrm{MMgF}_{4}$ is more and more difficult [79]. The crystal structures of strontium- and barium tetrafluoromagnesate are shown in Fig. 10 with the same view along the $a$-axis.

\section{Solid solutions: $M_{x}^{a} M^{b}{ }_{1-x} F_{2}\left(M^{a}, M^{b}: C a, S r, B a, P b\right)$; $M_{1-x} \operatorname{Ln}_{x} F_{2+x}$ (M: Ca, Sr; Ln: Y, Eu)}

The mechanochemical synthesis of solid solutions of alkaline earth metal fluorides with fluorite structure according to Eq. (3) is very easily possible $[80,81]$.

$(1-x) \mathrm{M}^{\mathrm{a}} \mathrm{R}_{2}+x \mathrm{M}^{\mathrm{b}} \mathrm{R}_{2}+2 \mathrm{NH}_{4} \mathrm{~F} \quad \longrightarrow \quad \mathrm{M}_{1-x}^{\mathrm{a}} \mathrm{M}_{x}^{\mathrm{b}} \mathrm{F}_{2}+2 \mathrm{NH}_{3}+2 \mathrm{HR}$

thermal treatment in a furnace using quasi-isobar crucibles. Instead, the use of $\beta-\mathrm{AlF}_{3} \cdot 3 \mathrm{H}_{2} \mathrm{O}$ as fluorinating agent allows mechanochemical reactions with aluminium hydroxides and as a result the formation of aluminium hydroxide fluorides, $\mathrm{AlF}_{x}(\mathrm{OH})_{3-x} \cdot n \mathrm{H}_{2} \mathrm{O}$. Dependent on the respective supplied $\mathrm{Al} / \mathrm{F}$ molar ratio, crystalline $(\mathrm{Al} / \mathrm{F}<1)$ or $\mathrm{X}$-ray amorphous compounds $(\mathrm{Al} / \mathrm{F}>1)$ are formed [75-78].

The mechanochemical synthesis of aluminium fluoride $\mathrm{AlF}_{3}$, however, is not possible.

\section{Complex fluorides: $\mathrm{MF}_{2}-\mathrm{MgF}_{2}\left(\mathrm{MMgF}_{4}, \mathrm{M}: \mathrm{Ca}, \mathrm{Sr}, \mathrm{Ba}\right)$}

The mechanochemical synthesis of $\mathrm{BaMgF}_{4}$ using the binary fluorides $\mathrm{BaF}_{2}$ and $\mathrm{MgF}_{2}$ [37] is also possible by applying the fluorination of fluorine-free starting materials with ammonium fluoride directly in the mill (Eq. (1), [79]). Provided that the respective molar ratio of reactants is used, a direct and stable formation of tetrafluoromagnesates
(R: $\mathrm{OH}^{-}, \mathrm{OAc}^{-}, 0.5 \mathrm{CO}_{3}^{2-}$ )

Equation (3) holds for those cations $\mathrm{M}^{\mathrm{a}}$ and $\mathrm{M}^{\mathrm{b}}$ which form themselves binary fluorides with fluorite structure. The mutual substitution of cations on their lattice positions was directly proven with the help of ${ }^{19} \mathrm{~F}$ solid-state NMR spectroscopy. Fluorine is tetrahedrally coordinated by four cations in the cubic fluorite structure $\left(\left[\mathrm{FM}_{4}\right]\right)$. Therefore, five possibilities exist for the local coordination of fluorine on the formation of solid solutions (Eq. 3): $\left[\mathrm{FM}_{4-x}^{\mathrm{a}} \mathrm{M}_{x}^{\mathrm{b}}\right]$, with $0 \leq x \leq 4$. Exemplarily, a ${ }^{19} \mathrm{~F}$ MAS NMR spectrum of $\mathrm{Sr}_{0.5} \mathrm{~Pb}_{0.5} \mathrm{~F}_{2}$ with all five possible fluorine coordinations and their respective assignments is shown in Fig. 11.

From literature data it was already known that the formation of solid solutions of different fluorides has an additional positive effect on fluoride ion conductivities. These findings were verified for solid solutions mechanochemically synthesized according to Eq. (3). The DC fluoride ion conductivities shown in Fig. 12 for the combination of cations $\mathrm{Ba}-\mathrm{Pb}$ are distinctly higher than those for nanocrystalline $\mathrm{PbF}_{2}$, which is known as an excellent fluoride ion conductor. 


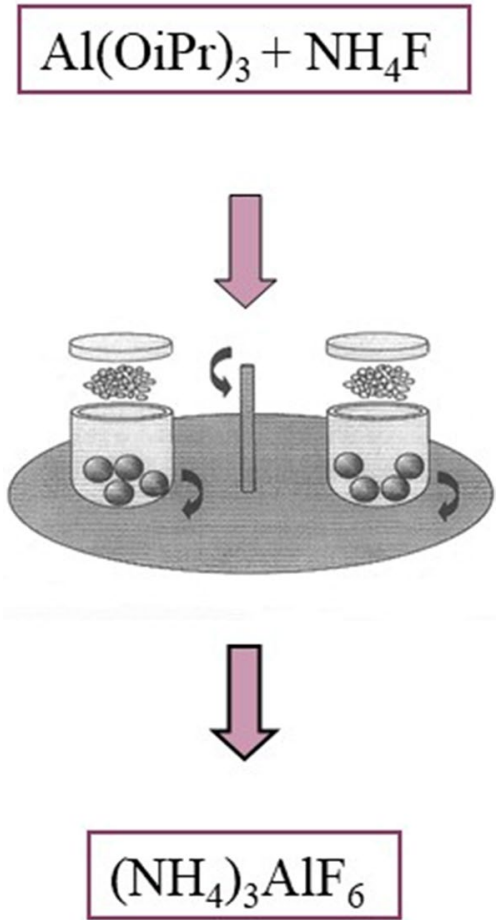

Fig. 8 Scheme for the mechanochemical synthesis of ammonium hexafluoroaluminate in a planetary mill. Reproduced from [71]. Copyright 2009 Elsevier Masson SAS. All rights reserved

A mechanochemical fluorination with $\mathrm{NH}_{4} \mathrm{~F}$ according to Eq. (3) is likewise successful for a doping with rare earths $[82,83]$. For a doping with $\mathrm{Eu}^{3+}$ cations it was shown that the solvent-free mechanochemical synthesis route results in nanocrystalline fluorides with remarkably long luminescence lifetimes of the excited states of europium [83]. The

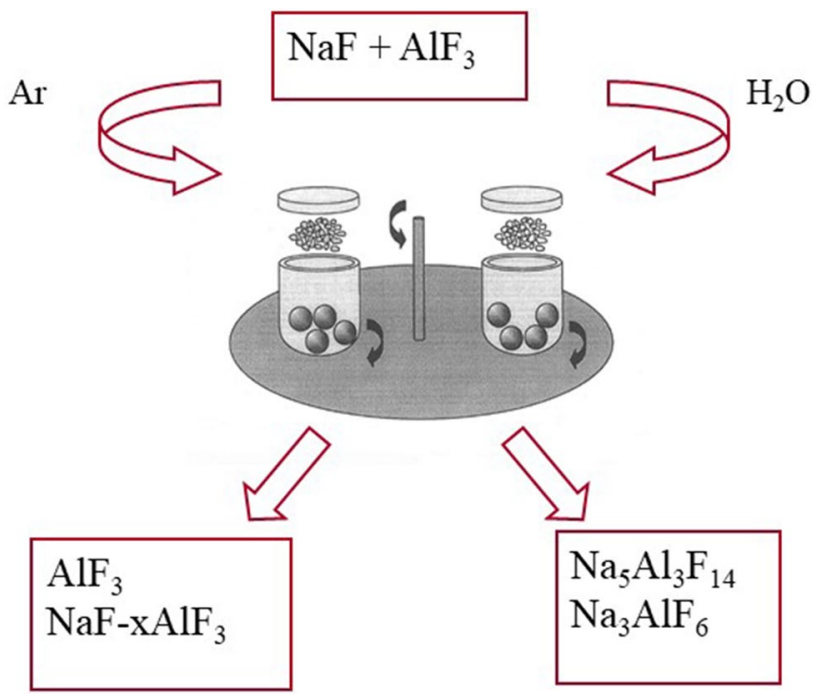

Fig. 9 Survey of the influence of humidity on the mechanochemical reaction between $\mathrm{NaF}$ and $\mathrm{AlF}_{3}$, leading to a different composition of the resulting powder mixtures. The main component is given in the upper line of each product box: left side, products obtained by milling under $\mathrm{Ar}$ atmosphere; right side, products obtained by milling in humid atmosphere. Reproduced from [74]. Copyright 2008 Elsevier Masson SAS. All rights reserved

latter opens additional interesting optical applications for such fluorides.

\section{Fluorine-containing coordination polymers of alkaline earth metals}

This overview finishes with some future prospects of ongoing research projects on the mechanochemical synthesis of fluorine-containing coordination polymers of alkaline earth metals.

In general, two principal possibilities exist for the implementation of fluorine in such compounds. Either fluorine is introduced with the perfluorinated organic compound
Fig. 10 Crystal structures of $\mathrm{SrMgF}_{4}(\mathbf{a})$ and $\mathrm{BaMgF}_{4}(\mathbf{b})$. Reproduced from [79]. Copyright 2015 Elsevier Masson SAS. All rights reserved a

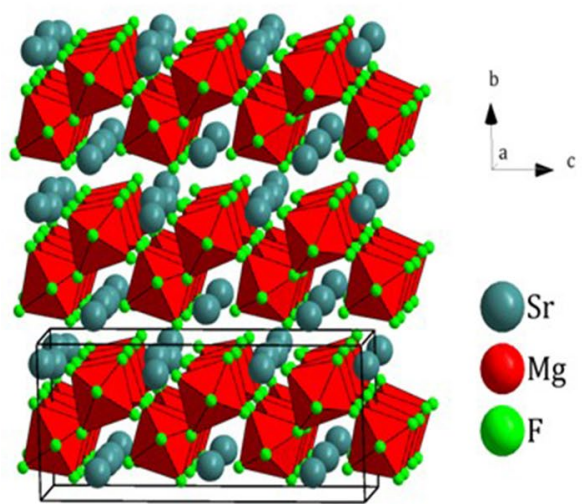

b

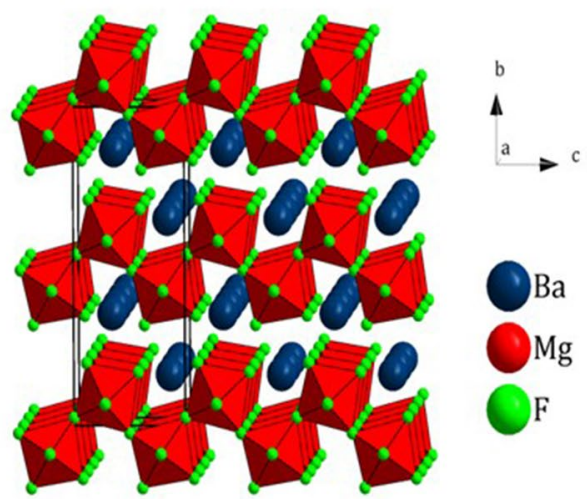


Fig. 11 Experimental (blue) and calculated (red) ${ }^{19} \mathrm{~F}$ MAS NMR spectrum of $\mathrm{Sr}_{0.5} \mathrm{~Pb}_{0.5} \mathrm{~F}_{2}$ along with the assignment of ${ }^{19} \mathrm{~F}$ resonances to the five possible local structural units $\left[\mathrm{FM}_{x} \mathrm{~Pb}_{4-x}\right]$. Doublet signals are due to the visible scalar coupling $J_{\mathrm{F}-\mathrm{Pb}}$. Reproduced from [81]. Copyright 2018 Elsevier Masson SAS. All rights reserved

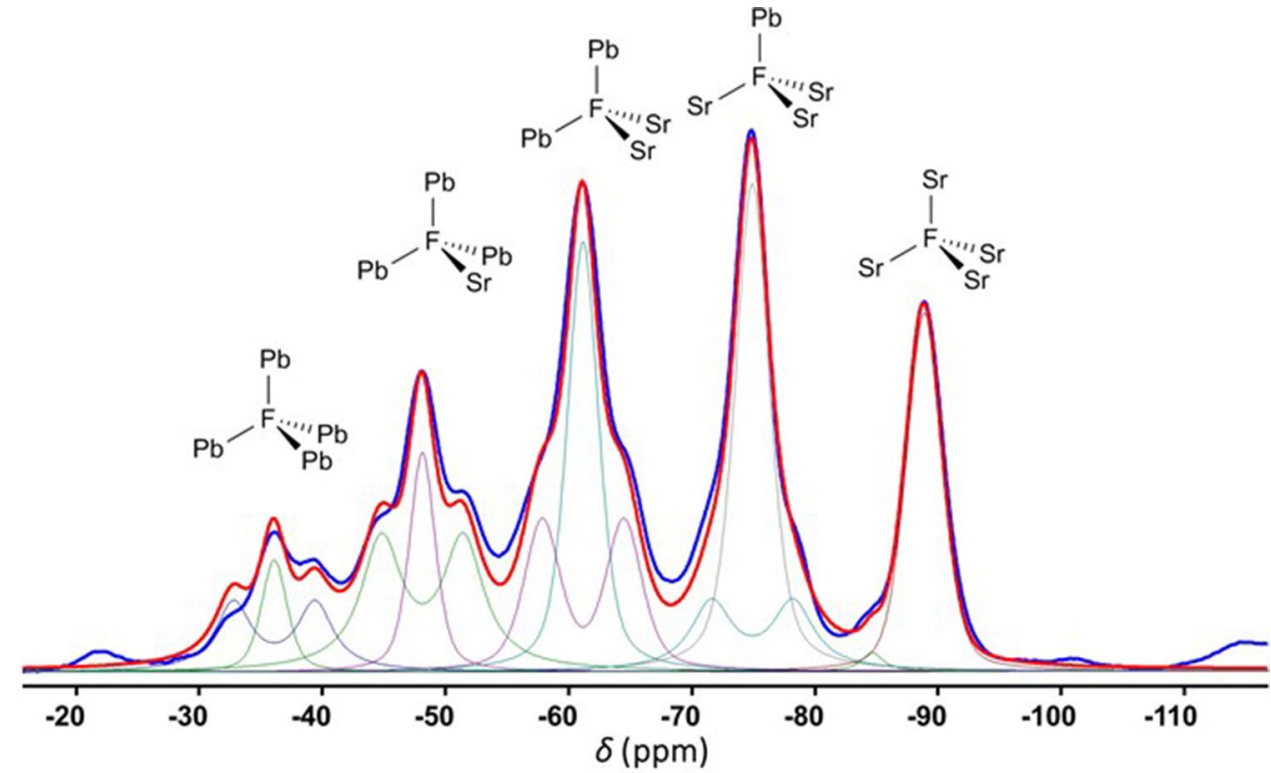

(linker) (Eq. 4) or the fluorination of the reactants takes place with ammonium fluoride directly in the mill (Eq. 5). the mechanochemical synthesis does not allow the formation of single crystals [86-92]. Figure 13 gives an insight into the

$\mathrm{M}(\mathrm{OH})_{2}+0.5 \mathrm{H}_{2} \mathrm{p}-\mathrm{BDC}+\mathrm{NH}_{4} \mathrm{~F} \rightarrow \mathrm{MF}(\mathrm{p}-\mathrm{BDC})_{0.5}+\mathrm{NH}_{3}+2 \mathrm{H}_{2} \mathrm{O}$

$\left(\mathrm{H}_{2} p-\mathrm{BDC}-\mathrm{F}_{4}\right.$ : tetrafluoroterephthalic acid (tetrafluoro-para-benzenedicarboxylic acid))

Initially it was shown that the simple mechanochemical synthesis using alkaline earth metal hydroxides and terephthalic acid $\left(\mathrm{H}_{2} p\right.$-BDC, fluorine-free) is possible. $\mathrm{Ca}, \mathrm{Sr}$, and $\mathrm{Ba}$ terephthalate hydrates were formed in this way up to partially new compounds [84, 85]. Hydroxides or hydroxide hydrates were ideal starting materials, as found before for the synthesis of binary fluorides. Moreover, a synthesis protocol was available, which can be completely transferred to the synthesis with perfluorinated linkers.

Use of different tetrafluorobenzenedicarboxylic acids with carboxylic groups in para, meta and ortho position $\left(\mathrm{H}_{2} p\right.$-BDC- $\left.\mathrm{F}_{4}, \mathrm{H}_{2} m-\mathrm{BDC}-\mathrm{F}_{4}, \mathrm{H}_{2} o-\mathrm{BDC}-\mathrm{F}_{4}\right)$ allowed numerous so far unknown coordination polymers to be mechanochemically synthesized. Structure and properties of these new compounds were comprehensively characterized. Standard analytical methods like X-ray diffraction, solidstate NMR and FTIR spectroscopies, but also methods of thermal analysis, elemental analysis, BET measurements and methods of dynamic gas absorption (DVS, dynamic vapour sorption) were employed. Structure determinations were performed from X-ray diffraction powder data, since structure of $\mathrm{Ca}(\mathrm{Sr})\left(p-\mathrm{BDC}-\mathrm{F}_{4}\right) \cdot 4 \mathrm{H}_{2} \mathrm{O}$, as one representative example of the numerous new compounds. Here, the alkaline earth metal cations $\mathrm{Ca}^{2+}\left(\mathrm{Sr}^{2+}\right)$ possess a nine-fold oxygen coordination $\left(\mathrm{Ca}(\mathrm{Sr}) \mathrm{O}_{9}\right.$, Fig. 13) [86].

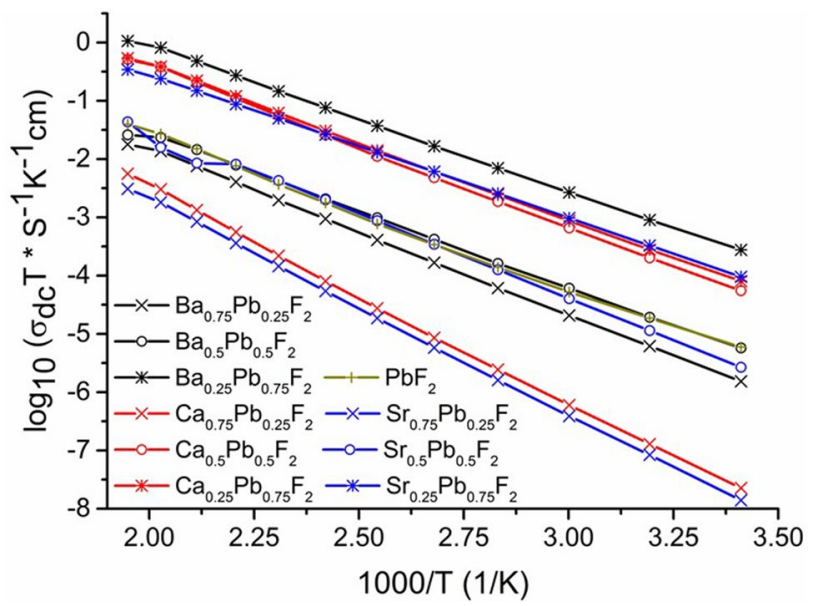

Fig. 12 Arrhenius plot of the DC conductivities of $\mathrm{M}_{x} \mathrm{~Pb}_{1-x} \mathrm{~F}_{2}$ samples, prepared with different cation ratios by milling $(8 \mathrm{~h})$ the corresponding metal acetates with ammonium fluoride. $\mathrm{PbF}_{2}$ was prepared by milling $(4 \mathrm{~h})$ of $\mathrm{Pb}(\mathrm{OAc})_{2} \cdot 3 \mathrm{H}_{2} \mathrm{O}$ with $\mathrm{NH}_{4} \mathrm{~F}$. Reproduced from [81]. Copyright 2018 Elsevier Masson SAS. All rights reserved 


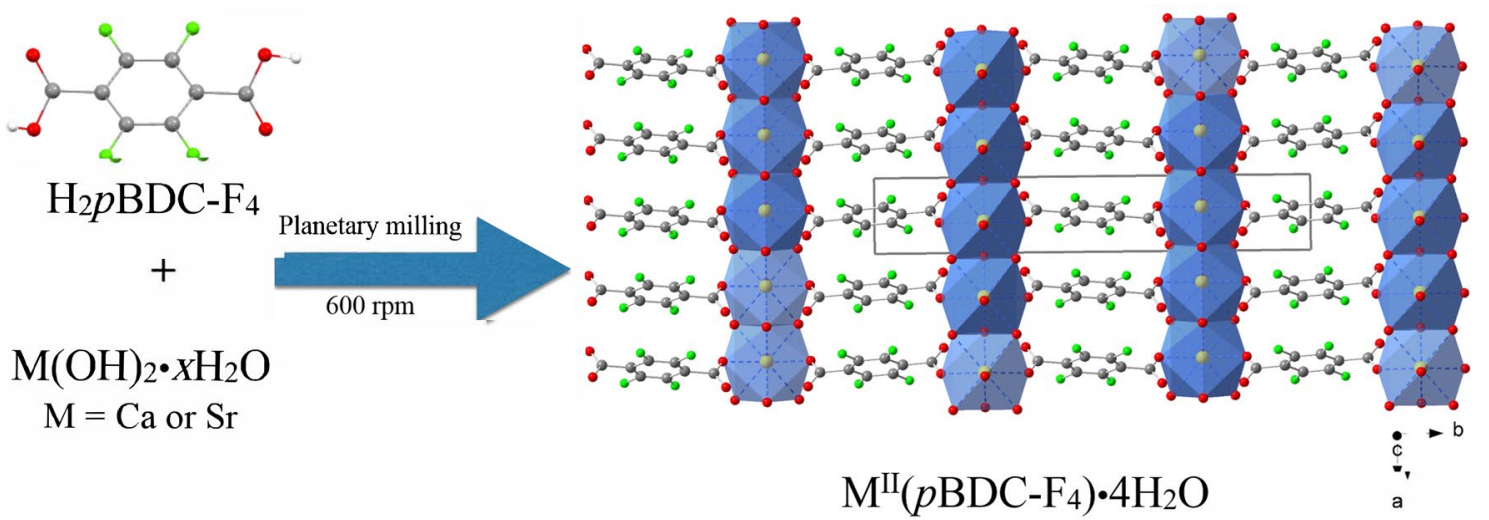

Fig. 13 Graphical abstract for the mechanochemical synthesis of $\mathrm{Ca}(\mathrm{Sr})$-tetrafluoroterephthalate-tetrahydrates, as well as detail of the structure. Reprinted with permission from [86]. Copyright (2016) American Chemical Society

Finally, in 2018 we reported the first mechanochemical synthesis of a coordination polymer with a direct barium-fluorine bond, in $\mathrm{BaF}-$ benzenedicarboxylate $\mathrm{BaF}(p \mathrm{BDC})_{0.5}$ [93]. Both barium hydroxide and barium acetate can act as the barium source (Eq. 5); they are partially fluorinated by $\mathrm{NH}_{4} \mathrm{~F}$ if an organic linker is additionally present. Figure 14 gives a schematic overview of different reaction opportunities during milling of $\mathrm{Ba}(\mathrm{OH})_{2}$ with organic linkers and/or $\mathrm{NH}_{4} \mathrm{~F}$.

The barium terephthalate system was chosen to study the influence of different fluorine positions (fluorinated organic linker vs. direct $\mathrm{Ba}-\mathrm{F}$ bond) on the lifetime of the excited states when doped with lanthanide ions $\left(\mathrm{Eu}^{3+}, \mathrm{Tb}^{3+}\right)$. Here, the coordination polymer with a direct metal-fluorine bond shows the highest lifetime of the excited states of lanthanides $\left(\mathrm{Eu}^{3+}, \mathrm{Tb}^{3+}\right.$ or $\left.\mathrm{Eu}^{3+} / \mathrm{Tb}^{3+}\right)$ [94].

Further new 2D networks with a direct metal-fluorine bond $\left(\mathrm{MF}\left(\mathrm{CH}_{3} \mathrm{COO}\right), \mathrm{M}\right.$ : $\left.\mathrm{Ca}, \mathrm{Sr}, \mathrm{Ba}, \mathrm{Pb}\right)$ were synthesized using acetates, ammonium fluoride and $\mathrm{H}_{2} p$-BDC (in the case of alkaline earth metal cations) by the mechanochemical route. Crystal structures were solved from the powder data [95]. Their local structures and crystal structures are depicted in Figs. 15 and 16. The only exception is the calcium compound, which cannot be obtained phase pure. As in the cubic alkaline earth metal fluorides, fluorine is also in acetate fluorides four-fold coordinated by the cations ([95], Figs. 15, 16). A comparison of structure and properties of fluorinated and non-fluorinated Ba-coordination polymers is published in Ref. [96], comparing barium acetate fluoride, barium trifluoroacetate and barium acetate, i.e. comparing the different possibilities and consequences of fluorine integration into the networks. The fluorine position turned out

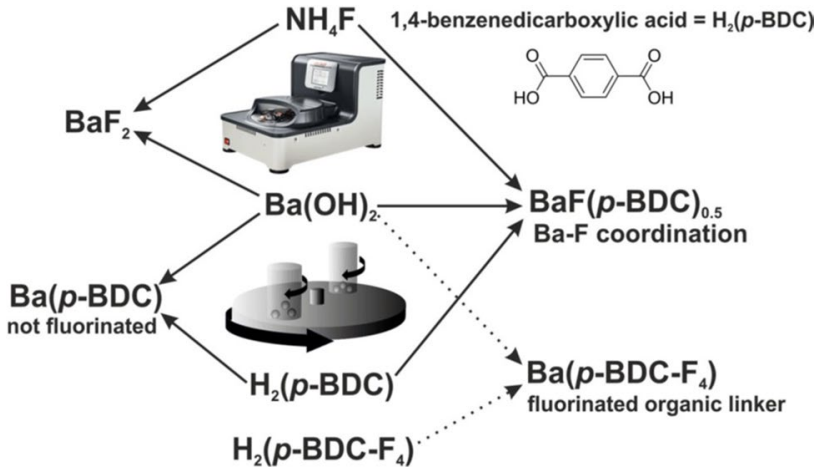

Fig. 14 Possible reaction products obtained by milling of $\mathrm{Ba}(\mathrm{OH})_{2}$ with terephthalic acid $\left(\mathrm{H}_{2}(p-\mathrm{BDC})\right)$ and/or ammonium fluoride $\left(\mathrm{NH}_{4} \mathrm{~F}\right)$. The milling products are given on the left and right side of the figure by combination of two or three reactants (middle) at a time. Reprinted from [93] with permission from Springer Nature, Copyright (2018)

to be crucial for material properties like thermal stability, vapour sorption behaviour and electrochemical performance [96].

\section{Conclusion}

Beside a short introduction into general and historical aspects of mechanochemistry, the present lecture text focused on the mechanochemical activation and mechanochemical syntheses of fluoride solids, especially of alkaline earth metal fluorides and fluorine-containing coordination polymers of alkaline earth metals. 
Fig. 15 Local environment and crystal structure of compounds $\mathrm{MF}\left(\mathrm{CH}_{3} \mathrm{COO}\right)$ (M: Ba or $\mathrm{Sr}$ ). a Crystal structure showing the local fluorine coordination (green polyhedra) and metal coordination sphere (blue polyhedra); b layered structure of the $2 \mathrm{D}$ coordination polymer (blue, metal; black, carbon; green, fluorine; red, oxygen; grey, hydrogen). Reproduced from Ref. [95] with permission from The Royal Society of Chemistry a

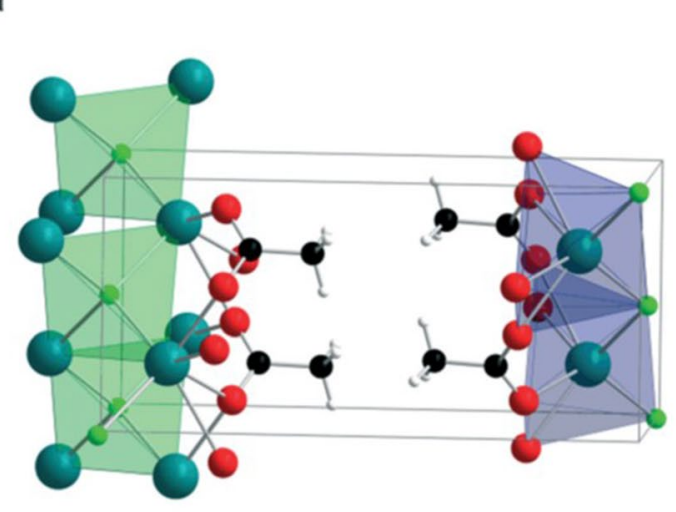

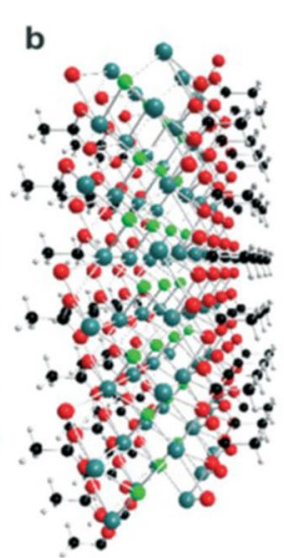

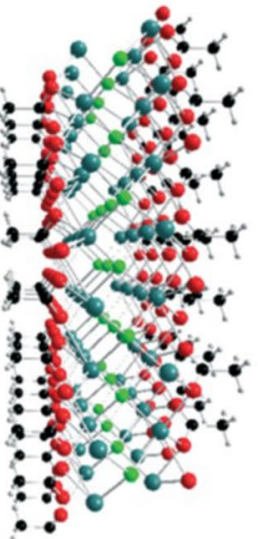

a

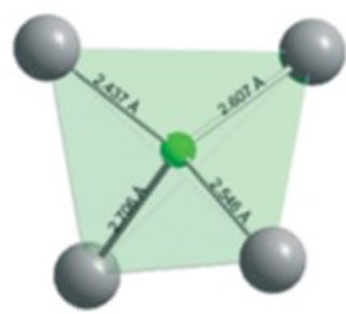

b

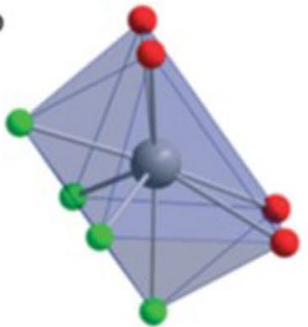

c

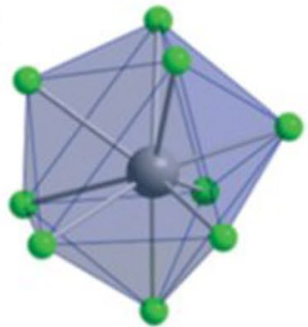

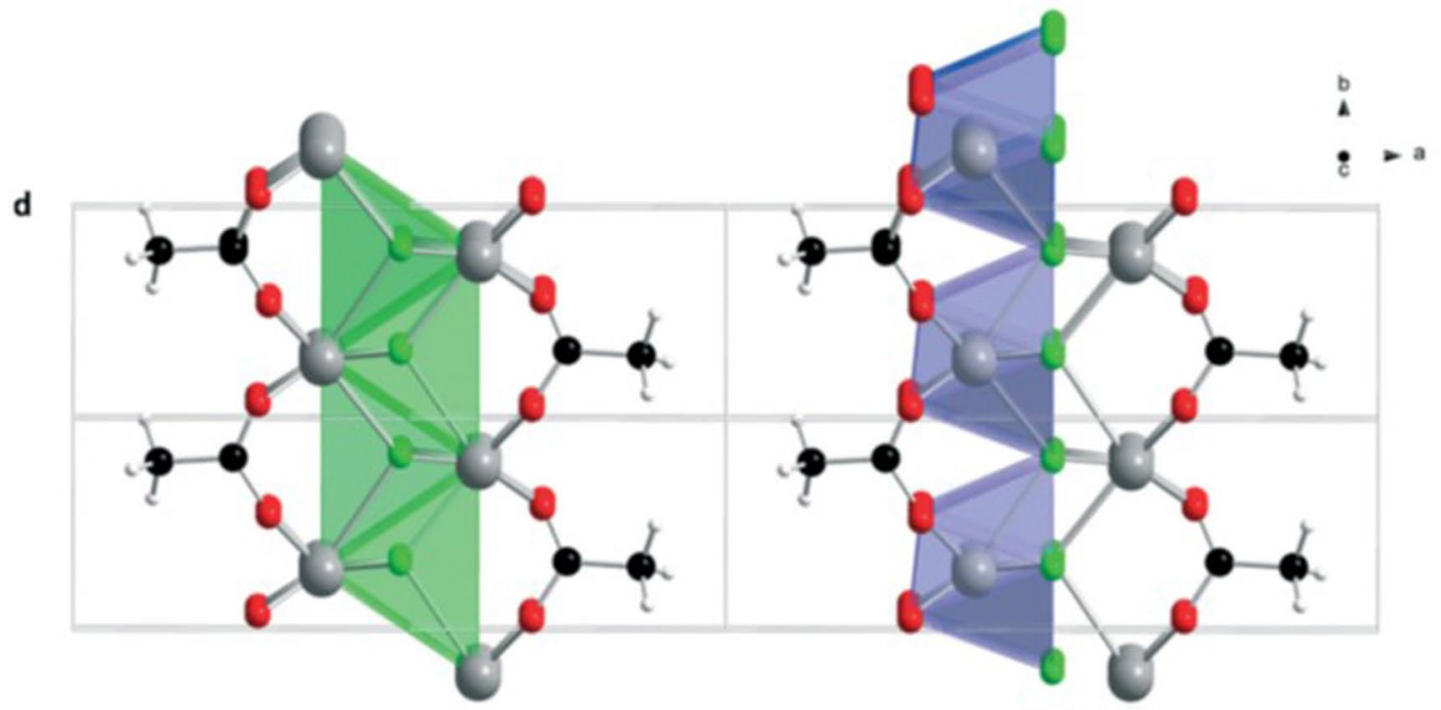

Fig. 16 Local environment and crystal structure of compound $\mathrm{PbF}\left(\mathrm{CH}_{3} \mathrm{COO}\right)$. a Coordination around the $\mathrm{F}$ atom; b coordination around $\mathrm{Pb}$ with four oxygen atoms and four fluorine atoms; $\mathbf{c}$ coordination around $\mathrm{Pb}$ in $\alpha-\mathrm{PbF}_{2}$ for comparison; $\mathbf{d}$ layered $2 \mathrm{D}$ crystal

The simple mechanochemical synthesis route for binary fluorides, for complex fluorides, for fluoride solid solutions and also for fluorine-containing coordination polymers shows that this solvent-free synthesis strategy can be usedvia particle grinding - to build up new compounds also for these classes of inorganic materials and inorganic-organic hybrid materials, respectively. The observed interesting structure with the fluorine polyhedra (green) and $\mathrm{Pb}$ polyhedra (blue) (grey, metal; black, carbon; green, fluorine; red, oxygen; light grey, hydrogen). Reproduced from Ref. [95] with permission from The Royal Society of Chemistry

properties of those compounds, especially regarding fluoride ion conductivities and luminescence properties in the case of doping, combined with their easy access via mechanochemistry, are expected to result in interesting applications in the near future. For the new fluorine-containing coordination polymers of alkaline earth metals, studies of their catalytical, 
optical, electrochemical and gas sorption behaviour are still at the beginning.

Acknowledgements The author kindly acknowledges the Graduate School GRK 1582/2 "Fluorine as a Key Element" and the Collaborative Research Centre CRC 1109 "Understanding of Metal Oxide/ Water Systems" of the DFG (Deutsche Forschungsgemeinschaft) for financial support.

Funding Open Access funding enabled and organized by Projekt DEAL.

Open Access This article is licensed under a Creative Commons Attribution 4.0 International License, which permits use, sharing, adaptation, distribution and reproduction in any medium or format, as long as you give appropriate credit to the original author(s) and the source, provide a link to the Creative Commons licence, and indicate if changes were made. The images or other third party material in this article are included in the article's Creative Commons licence, unless indicated otherwise in a credit line to the material. If material is not included in the article's Creative Commons licence and your intended use is not permitted by statutory regulation or exceeds the permitted use, you will need to obtain permission directly from the copyright holder. To view a copy of this licence, visit http://creativecommons.org/licenses/by/4.0/.

\section{References}

1. Baláž M, Vella-Zarb L, Hernández JG, Halasz I, Crawford DE, Krupička M, André V, Niidu A, Garcia F, Maini L, Colacino E (2019) Mechanochemistry: a disruptive innovation for the industry of the future. Chim Oggi-Chem Today 37(6):32-34

2. Takacs L (2013) The historical development of mechanochemistry. Chem Soc Rev 42:7649-7659

3. Baláž P (2008) Mechanochemistry in nanoscience and minerals engineering. Springer, Berlin

4. Kipp S, Šepelák V, Becker KD (2005) Chemie mit dem Hammer-Mechanochemie. Chem uns Zeit 39:384-392

5. Takacs L (2018) Two important periods in the history of mechanochemistry. J Mater Sci 53:13324-13330

6. Ostwald W (1919) Die chemische Literatur und die Organisation der Wissenschaft. In: Ostwald, HW, Drucker C (eds) Handbuch der Allgemeinen Chemie, Band I, Akademische Verlagsgesellschaft mbH., Leipzig

7. Fuentes A (2018) Special section: mechanochemical synthesis. J Mater Sci 53(19):13319-14001

8. Bolm C, Hernández JG (2019) Mechanochemie gasförmiger Reaktanten. Angew Chem 131:3320-3335

9. James S, Friscic T (eds) (2013) Mechanochemistry themed issue of Chem Soc Rev 42(18):7487-7740

10. Heinicke G (1984) Tribochemistry. Akademie-Verlag, Berlin

11. Senna M (2017) How we can make solids more reactive? Basics of mechanochemistry and recent new insights. Chem Texts 3:4. https://doi.org/10.1007/s40828-017-0041-0

12. Ashokkumar M (2018) Introductory text to sonochemistry. Chem Texts 4:7. https://doi.org/10.1007/s40828-018-0061-4

13. Thiessen KP (1979) Energetische Randbedingungen tribochemischer Prozesse. I. Z Phys Chem (Leipzig) 260:403-409

14. Thiessen PA, Heinicke G, Meyer K (1960) Forschen und Wirken. Festzeitschrift zur 150-Jahrfeier der Humboldt-Universität, chapt. $1, \mathrm{p} 15$

15. Fischer F, Greiser S, Pfeifer D, Jäger C, Rademann K, Emmerling F (2016) Mechanochemically induced conversion of crystalline benzamide polymorphs by seeding. Angew Chem Int Ed 55:14282-14285

16. Lee J, Zhang Q, Saito F (2001) Mechanochemical synthesis of ternary fluorides with perovskite structures. Chem Lett 30(7):700-701

17. Lu J, Zhang Q, Saito F (2002) Mechanochemical synthesis of nano-sizedcomplex fluorides from pair of different constituent fluoride compounds. Chem Lett 31(12):1176-1177

18. Lee J, Zhang Q, Saito F (2001) Mechanochemical synthesis of lanthanum oxyfluoride by grinding lanthanum oxide with poly(vinylidene fluoride). Ind Eng Chem Res 40:4785-4788

19. Kavun VY, Uvarov NF, Slobodyuk AB, Ulikhin AS, Telin IA, Goncharuk VK (2017) Ionic mobility and elektrophysical properties of Solid solutions in $\mathrm{PbF}_{2}-\mathrm{SbF}_{3}$ and $\mathrm{PbF}_{2}-\mathrm{SnF}_{2}-\mathrm{SbF}_{3}$ systems. Russ J Electrochem 53(8):884-892

20. Kavun VY, Uvarov NF, Slobodyuk AB, Merkulov EB, Polyantsev MM (2018) Ion mobility and transport properties of bismuth fluoride-containing solid solutions with tysonite-type structure. J Solid State Chem 263:203-207

21. Patro LN, Hariharan K (2012) Mechanical milling: an alternative approach forenhancing the conductivity of $\mathrm{SnF}_{2}$. Mater Lett 80:26-28

22. Patro LN, Hariharan K (2013) Fast fluoride ion conducting materials in solid stateionics: an overview. Solid State Ionics 239:41-49

23. Mohammad I, Witter R, Fichtner M, Anji Reddy M (2018) Roomtemperature, rechargeable solid-state fluoride-ion batteries. Appl Energy Mater 1:4766-4775

24. Patro LN, Hariharan K (2011) Influence of synthesis methodology on the ionic transport properties of $\mathrm{BaSnF}_{4}$. Mater Res Bull 46:732-737

25. Kumar M, Yamada K, Okuda T, Sekhon SS (2003) Temperature dependence of F-19 NMR and ion transport parameters of fluoride ion conductors $\mathrm{SnF}_{2}-\mathrm{PbF}_{2}$ and $2 \mathrm{SnF}_{2}-\mathrm{NH}_{4} \mathrm{~F}$ prepared by mechanical milling. Phys Stat Sol B 239(2):432-438

26. Kumar M, Sekhon SS (2001) Mixed fluoride ion conductors prepared by a mechanical milling technique: effect of grain size and strain on the ionic conductivity. J Phys D Appl Phys 34(19):2995-3002

27. Fujisaki F, Mori K, Yonemure M, Ishikawa Y, Kamiyama T, Otomo T, Matsubara E, Fukunaga T (2017) Mechanical synthesis and structural properties of the fast fluoride-ion conductor $\mathrm{PbSnF}_{4}$. J Solid State Chem 253:287-293

28. Murakami M, Morita Y, Mizuno M (2017) ${ }^{19} \mathrm{~F} /{ }^{119} \mathrm{Sn} /{ }^{207} \mathrm{~Pb}$ NMR studies in ion dynamics in tetragonal $\mathrm{PbSnF}_{4}$ : spectroscopic evidence for defect-driven conductivity. J Phys Chem C 121:2677-2634

29. Uno M, Onitsuka M, Ito Y, Yoshikado S (2005) Synthesis and evaluation of $\mathrm{Pb}_{1-x} \mathrm{Sn}_{x} \mathrm{~F}_{2}$ by mechanical milling. Solid State Ionics 176:2493-2498

30. Molaiyan P, Witter R (2019) Crystal phase and surface defect driven synthesis of $\mathrm{Pb}_{1-x} \mathrm{Sn}_{x} \mathrm{~F}_{2}$ solid solution electrolyte for fluoride ion batteries. J Electroanal Chem 845:154-159

31. Düvel A, Wilkening M, Uecker R, Heitjans P (2010) Ion transport properties of the inverse perovskite $\mathrm{BaLiF}_{3}$ prepared by highenergy ball milling. Diffus Fundam 12:104-105

32. Düvel A, Wilkening M, Uecker R, Feldhoff A, Heitjans P (2010) Mechanosynthesized nanocrystalline $\mathrm{BaLiF}_{3}$ : the impact of grain boundaries and structural disorder on ionic transport. Phys Chem Chem Phys 12:11251-11262

33. Düvel A, Wilkening M, Wegner S, Feldhoff A, Sepelak V, Heitjans $P$ (2011) Ion conduction and dynamics in mechanosynthesized nanocrystalline $\mathrm{BaLiF}_{3}$. Solid State Ionics 184:65-69

34. Düvel A, Morgan LM, Cibin G, Pickup D, Chadwick AV, Heitjans P, Sayle DC (2018) Tunung antisite defect density in perovskite$\mathrm{BaLiF}_{3}$ via cycling between ball milling and heating. J Phys Chem Lett 9:5121-5124 
35. Düvel A, Wegner S, Efimov K, Feldhoff A, Heitjans P, Wilkening $M$ (2011) Access to metastable complex ion conductors via mechanosynthesis: preparation, microstructure and conductivity of $(\mathrm{Ba}, \mathrm{Sr}) \mathrm{LiF}_{3}$ with inverse perovskite structure. J Mater Chem 21:6238-6250

36. Düvel A, Morgan LM, Chandran CV, Heitjans P, Sayle DC (2018) Formation and elimimination of anti-site defects during crystallization in perovskite $\mathrm{Ba}_{1-x} \mathrm{Sr}_{x} \mathrm{LiF}_{3}$. Cryst Growth Des 18:2093-2099

37. Preishuber-Pflügl F, Wilkening M (2014) Evidence of low dimensional ion transport in mechanosynthesized nanocrystalline $\mathrm{BaMgF}_{4}$. Dalton Trans 43:9901-9908

38. Preishuber-Pflügl F, Wilkening M (2016) Mechanochemically synthesized fluorides: local structures and ion transport. Dalton Trans 45:8675-8687

39. van Wüllen L, Schiffmann JG, Kopp J, Liu Z, Kirchhain H, Düvel A, Heitjans P (2017) Development and application of novel NMR methodologies for the in situ characterization of crystallization processes of metastable crystalline materials. Z Kristallogr Cryst Mater 232:141-159

40. Wilkening M, Düvel A, Preishuber-Pflügl F, da Silva K, Breuer S, Šepelak V, Heitjans P (2017) Structure and ion dynamics of mechanosynthesized oxides and fluorides: access to nanocrystalline ceramics via high-energy ball milling-a short review. Z Kristallogr Cryst Mater 232:107-127

41. Gombotz M, Lunghammer S, Breuer S, Hanzu I, Preishuber-Pflüg1 F, Wilkening M (2019) Spatial confinement—rapid 2D F- diffusion in micro- and nanocrystalline $\mathrm{RbSn}_{2} \mathrm{~F}_{5}$. Phys Chem Chem Phys 21:1872-1883

42. Patro LN, Hariharan K (2009) Frequency dependent conduction caracteristics of mechanochemically synthesized $\mathrm{NaSn}_{2} \mathrm{~F}_{5}$. Mater Sci Eng B 162:173-178

43. Podgorbunsky AB, Usoltseva TI, Merkulov EB, Gnedenkov SV, Sinebryuhov SL (2016) Effect of aliovalent dopants on the electrophysical properties of mechanochemically synthesized $\mathrm{KSn}_{2} \mathrm{~F}_{5}$. Solid State Phenom 245:166-171

44. Feinauer M, Euchner H, Fichtner M, Anji Reddy M (2019) Unlocking the potential of fluoride-based solid electrolytes for solid-state lithium batteries. Appl Energy Mater 2:7196-7203

45. Düvel A, Ruprecht B, Heitjans P, Wilkening M (2011) Mixed alkaline earth effect in the metastable anion conductor $\mathrm{Ba}_{1-x} \mathrm{Ca}_{x} \mathrm{~F}_{2}$ $(0 \leq x \leq 1)$ : correlating long-range ion transport with local structures revealed by ultrafast ${ }^{19} \mathrm{~F}$ MAS NMR. J Phys Chem C 115:23784-23789

46. Düvel A (2019) Ionic conductivity and structure of $\mathrm{M}_{1-x} \mathrm{~Pb}_{x} \mathrm{~F}_{2}$ $(\mathrm{M}=\mathrm{Ca}, \mathrm{Sr}, \mathrm{Ba})$ solid solutions prepared by ball milling. Dalton Trans 48(3):859-871

47. Ruprecht B, Wilkening M, Steuernagel S, Heitjans P (2008) Anion diffusivity in highly conductive nanocrystalline $\mathrm{BaF}_{2}: \mathrm{CaF}_{2}$ composites prepared by high-energy ball milling. J Mater Chem 18:5412-5416

48. Ruprecht B, Wilkening M, Feldhoff A, Steuernagel S, Heitjans $\mathrm{P}$ (2009) High anion conductivity in a ternary non-equilibrium phase of $\mathrm{BaF}_{2}$ and $\mathrm{CaF}_{2}$ with mixed cations. Phys Chem Chem Phys 11:3071-3081

49. Lunghammer S, Düvel A, Posch P, Kunert B, Resel R, Wilkening $M$ (2019) Self-diffusion and ionic exchange in mechanosynthesized, nanocrystalline solid solutions of $\mathrm{PbF}_{2}$ and $\mathrm{CaF}_{2}-{ }^{19} \mathrm{~F} 2 \mathrm{D}$ NMR visualizes the fluorine hopping preferences. Solid State Ionics 343:115067. https://doi.org/10.1016/j.ssi.2019.115067

50. Breuer S, Stanje B, Pregartner V, Lunghammer S, Hanzu I, Wilkening $M$ (2018) Fluorine translational anion dynamics in nanocrystalline ceramics: $\mathrm{SrF}_{2}-\mathrm{YF}_{3}$ solid solutions. Crystals 8:122. https://doi.org/10.3390/cryst8030122
51. Breuer S, Lunghammer S, Kiesl A, Wilkening M (2018) F anion dynamics in cation-mixed nanocrystalline $\mathrm{LaF}_{3}: \mathrm{SrF}_{2}$. J Mater Sci 53:13669-13681

52. Düvel A, Bednarcik J, Sepelak V, Heitjans P (2014) Mechanosynthesis of the fast fluoride ion conductor $\mathrm{Ba}_{1-x} \mathrm{La}_{x} \mathrm{~F}_{2+x}$ : from the fluorite to the tysonite structure. J Phys Chem C 118:7117-7129

53. Sobolev BP, Sviridov IA, Fadeeva VI, Sul'yanov SN, Sorokin NI, Zhmurova ZI, Khodos II, Avilov AS, Zaporozhets MA (2008) Mechanochemical synthesis of nonstoichiometric nanocrystals $\mathrm{La}_{1-y} \mathrm{Ca}_{y} \mathrm{~F}_{3-y}$ with a tysonite structure and nanoceramic materials from $\mathrm{CaF}_{2}$ snd $\mathrm{LaF}_{3}$ crystals. Cryst Rep 53:868-880

54. Molaiyan P, Witter R (2019) Mechanochemical synthesis of solidstate electrolyte $\mathrm{Sm}_{1-x} \mathrm{Ca}_{x} \mathrm{~F}_{3-x}$ for batteries and other electrochemical devices. Mater Lett 244:22-26

55. Slobodyuk AB, Usoltseva TI, Polyantsev MM, Kavun VY (2019) Ionic mobility in $\mathrm{Li}_{x} \mathrm{~K}_{1-x} \mathrm{Sn}_{2} \mathrm{~F}_{5}(x=0-0.15)$ solid solutions obtained by mechanochemical synthesis. Ionics 25:1481-1486

56. Patro LN, Hariharan K (2012) Ionic transport studies in $\mathrm{Sn}_{(1-x)} \mathrm{K}_{x} \mathrm{~F}_{(2-x)}$ type solid electrolytes. Mater Res Bull 47:2492-2497

57. Breuer S, Gombotz M, Pregartner V, Hanzu I, Wilkening M (2019) Heterogeneous $\mathrm{F}$ anion transport, local dynamics and electrochemical stability of nanocrystalline $\mathrm{La}_{1-x} \mathrm{Ba}_{x} \mathrm{~F}_{3-x}$. Energy Storage Mater 16:481-490

58. Gombotz M, Pregartner V, Hanzu I, Wilkening M (2019) Fluoride-ion batteries: on the electrochemical stability of nanocrystalline $\mathrm{La}_{0.9} \mathrm{Ba}_{0.1} \mathrm{~F}_{2.9}$ against metal electrodes. Nanomaterials 9:1517. https://doi.org/10.3390/nano9111517

59. Patro LN (2020) Role of mechanical milling on the synthesis and ionic transport properties of fast fluoride ion conducting materials. J Solid State Electr 24:2219-2232

60. Heitjans P, Indris S (2004) Fast diffusion in nanocrystalline ceramics prepared by ball milling. J Mater Sci 39:5091-5096

61. Scholz G, Dörfel I, Heidemann D, Feist M, Stösser R (2006) Nanocrystalline $\mathrm{CaF}_{2}$ particles obtained by high-energy ball milling. J Solid State Chem 179(4):1119-1128

62. Abdellatief M, Abele M, Leoni M, Scardi P (2013) Solid State magnetic resonance and $\mathrm{X}$-ray diffraction line profile analysis of heavily deformed fluorite. Thin Solid Films 530:44-48

63. Molaiyan P, Witter R (2019) Surface defect-enhanced conductivity of calcium fluoride for electrochemical applications. Mater Des Process Commun. https://doi.org/10.1002/mdp2.44

64. Molaiyan P, Witter R (2019) $\mathrm{CaF}_{2}$ solid-state electrolytes prepared by vapor pressure exposure and solid synthesis for defect and ionic conductivity tuning. Mater Des Process Commun. https://doi.org/ 10.1002/mdp2.76

65. Scholz G, König R, Petersen J, Angelow B, Dörfel I, Kemnitz E (2008) Mechanical activation of $\alpha-\mathrm{AlF}_{3}$ : changes in structure and reactivity. Chem Mater 10(16):5406-5431

66. Kemnitz E, Mahn S, Krahl T (2020) Nano metal fluorides: small particles with great properties. Chem Texts 6:19. https://doi.org/ 10.1007/s40828-020-00115-w

67. Dreger M, Scholz G, Kemnitz E (2012) An easy access to nanocrystalline alkaline earth metal fluorides-just by shaking. Solid State Sci 14:528-534

68. Scholz G, Meyer K, Düvel A, Heitjans P, Kemnitz E (2013) Fast ion conducting nanocrystalline alkaline earth fluorides simply prepared by mixing or manual shaking. Z Anorg Allg Chem 639(6):960-966

69. Heise M, Scholz G, Kemnitz E (2017) Mechanochemical synthesis of $\mathrm{PbF}_{2}$ by high energy ball milling. Solid State Sci. 72:41-46

70. Subirana Manzanares MA, Sanchez-Sala M, Pons J, Domingo C, Ayllón J (2016) Lead(II) fluoride particles synthesized by a straightforward mechanochemical route. Mater Lett 163:76-80 
71. Scholz G, Kemnitz E (2009) Mechanochemical synthesis of $\mathrm{AlF}_{3}$ using $\mathrm{NH}_{4} \mathrm{~F}$ as fluorinating agent—does it work? Solid State Sci $11: 676-682$

72. Lu J, Zhang Q, Wang J, Saito F (2004) Mechanochemical synthesis of ammonium hexafluorogallate. J Am Ceram Soc 87:1814-1816

73. Scholz G, Korup O (2006) High-energy ball milling — a possible synthesis route for cryolite and chaolite. Solid State Sci 8:678-684

74. Scholz G, Feist M, Kemnitz E (2008) On the influence of humidity on the mechanochemical reaction of $\mathrm{NaF}$ with $\mathrm{AlF}_{3}$. Solid State Sci 10:1640-1650

75. Scholz G, Brehme S, Balski M, König R, Kemnitz E (2010) Structure and properties of mechanochemically synthesized aluminium hydroxide fluoride phases $\mathrm{AlF}_{x}(\mathrm{OH})_{3-x} \cdot n \mathrm{H}_{2} \mathrm{O}$. Solid State Sci 12:1500-1506

76. Scalise V, Scholz G, Kemnitz E (2016) Mechanochemical synthesis of low-fluorine doped aluminium hydroxide fluorides. J Solid State Chem 243:154-161

77. Scalise V, Scholz G, Bertram R, Kemnitz E (2018) Identification of F-species after adsorption at the surface of milled and unmilled $\gamma-\mathrm{Al}_{2} \mathrm{O}_{3}$. Surf Interfaces 10:117-122

78. Scalise V, Scholz G, Kemnitz E (2018) On the influence of water on the mechanochemical synthesis of low F-doped Al-hydroxide fluorides. J Mater Sci 53(19):13660-13668

79. Scholz G, Breitfeld S, Krahl T, Düvel A, Heitjans P, Kemnitz $\mathrm{E}$ (2015) Mechanochemical synthesis of $\mathrm{MgF}_{2}-\mathrm{MF}_{2}$ composite systems (M: Ca, Sr, Ba). Solid State Sci 50:32-41

80. Heise M, Scholz G, Düvel A, Heitjans P, Kemnitz E (2016) Mechanochemical synthesis, structure and properties of solid solutions of alkaline earth metal fluorides: $\mathrm{M}_{1-x}^{\mathrm{a}} \mathrm{M}_{x}^{\mathrm{b}} \mathrm{F}_{2}(\mathrm{M}: \mathrm{Ca}, \mathrm{Sr}, \mathrm{Ba})$. Solid State Sci 60:65-74

81. Heise M, Scholz G, Düvel A, Heitjans P, Kemnitz E (2018) Mechanochemical synthesis, structure and properties of lead containing alkaline earth metal fluoride solid solutions $\mathrm{M}_{x} \mathrm{~Pb}_{1-x} \mathrm{~F}_{2}(\mathrm{M}: \mathrm{Ca}, \mathrm{Sr}$, Ba). Solid State Sci 77:45-53

82. Ritter B, Krahl T, Scholz G, Kemnitz E (2016) Local structures of solid solutions $\mathrm{Sr}_{1-x} \mathrm{Y}_{x} \mathrm{~F}_{2+x}$ with fluorite structure prepared by sol-gel and mechanochemical syntheses. J Phys Chem C 120:8992-8999

83. Heise M, Scholz G, Krahl T, Kemnitz E (2019) Luminescent properties of $\mathrm{Eu}^{3+}$ doped $\mathrm{CaF}_{2}, \mathrm{SrF}_{2}, \mathrm{BaF}_{2}$ and $\mathrm{PbF}_{2}$ powders prepared by high-energy ball milling. Solid State Sci 91:113-118

84. Scholz G, Emmerling F, Dreger M, Kemnitz E (2013) Mechanochemical synthesis and characterization of hydrated and dehydrated crystalline strontium terephthalates. Z Anorg Allg Chem 639:689-693

85. Scholz G, Abdulkader A, Kemnitz E (2014) Mechanochemical synthesis and characterization of alkaline earth metal terephthalates: $\mathrm{M}\left(\mathrm{C}_{8} \mathrm{H}_{4} \mathrm{O}_{4}\right) \cdot n \mathrm{H}_{2} \mathrm{O}(\mathrm{M}: \mathrm{Ca}, \mathrm{Sr}, \mathrm{Ba})$. Z Anorg Allg Chem 640:317-324
86. Al-Terkawi A, Scholz G, Emmerling F, Kemnitz E (2016) Mechanochemical synthesis, characterization, and structure determination of new alkaline earth metal-tetrafluoroterephthalate frameworks: $\mathrm{Ca}(\mathrm{pBDC}-\mathrm{F} 4) \cdot 4 \mathrm{H}_{2} \mathrm{O}, \mathrm{Sr}(\mathrm{pBDC}-\mathrm{F} 4) \cdot 4 \mathrm{H}_{2} \mathrm{O}$, and Ba(pBDC-F4). Cryst Growth Des 16:1923-1933

87. Al-Terkawi A, Scholz G, Buzanich AG, Reinsch S, Emmerling F, Kemnitz E (2017) Ca- and Sr-tetrafluoroisophthalates: mechanochemical synthesis, characterization, and ab initio structure determination. Dalton Trans 46:6003-6012

88. Al-Terkawi A, Scholz G, Emmerling F, Kemnitz E (2017) Strontium-coordination polymers based on tetrafluorophthalic and phthalic acids: mechanochemical synthesis, ab initio structure determination, and spectroscopic characterization. Dalton Trans 46:12574-12587

89. Al-Terkawi A, Scholz G, Prinz C, Ziemathies A, Emmerling F, Kemnitz E (2018) Hydrated and dehydrated Ca-coordination polymers based on benzene-dicarboxylates: mechanochemical synthesis, structure refinement, and spectroscopic characterization. CrystEngComm 20:946-961

90. Al-Terkawi A, Scholz G, Emmerling F, Kemnitz E (2018) Barium Coordination polymers based on fluorinated and fluorine-free benzene-dicarboxylates: mechanochemical synthesis and spectroscopic characterization. Solid State Sci 79:99-108

91. Al-Terkawi A, Scholz G, Emmerling F, Kemnitz E (2018) Catetrafluorophthalate and Sr-isophthalate: mechanochemical synthesis and characterization in comparison with other $\mathrm{Ca}$-and $\mathrm{Sr}-$ coordination polymers. Dalton Trans 47:5743-5754

92. Al-Terkawi A, Scholz G, Prinz C, Emmerling F, Kemnitz E (2019) $\mathrm{Ca}-, \mathrm{Sr}-$, and Ba-coordination polymers based on anthranilic acid via mechanochemistry. Dalton Trans 48:6513-6521

93. Breitfeld S, Scholz G, Emmerling F, Kemnitz E (2018) BaFbenzenedicarboxylate: the first mechanochemical synthesis of a new coordination polymer with a direct Ba-F bond. J Mater Sci 53(19):13682-13689

94. Zänker S, Scholz G, Krahl T, Prinz C, Emmerling F, Kemnitz $\mathrm{E}$ (2020) Luminescent properties of $\mathrm{Eu}^{3+} / \mathrm{Tb}^{3+}$ doped fluorine containing coordination polymers. Solid State Sci (in press)

95. Breitfeld S, Scholz G, Heise M, Emmerling F, Kemnitz E (2020) New 2D layered structures with direct fluorine-metal bonds: $\mathrm{MF}\left(\mathrm{CH}_{3} \mathrm{COO}\right)(\mathrm{M}: \mathrm{Sr}, \mathrm{Ba}, \mathrm{Pb})$. CrystEngComm 22:2772-2780

96. Zänker S, Scholz G, Xu W, Pinna N, Emmerling F, Kemnitz E (2020) Structure and properties of fluorinated and non-fluorinated Ba-coordination polymers - the position of fluorine makes the difference. Z Anorg Allg Chem (in press)

Publisher's Note Springer Nature remains neutral with regard to jurisdictional claims in published maps and institutional affiliations. 